Portland State University

PDXScholar

\title{
Student Outcomes, Educational Technology, And Assessment In Large Classrooms: Effects On Planned Behavior
}

Tanya Leigh Ostrogorsky

Portland State University

Follow this and additional works at: https://pdxscholar.library.pdx.edu/open_access_etds

Part of the Child Psychology Commons, and the School Psychology Commons

Let us know how access to this document benefits you.

\section{Recommended Citation}

Ostrogorsky, Tanya Leigh, "Student Outcomes, Educational Technology, And Assessment In Large Classrooms: Effects On Planned Behavior" (1997). Dissertations and Theses. Paper 5726.

https://doi.org/10.15760/etd.7597

This Thesis is brought to you for free and open access. It has been accepted for inclusion in Dissertations and Theses by an authorized administrator of PDXScholar. Please contact us if we can make this document more accessible: pdxscholar@pdx.edu. 


\section{THESIS APPROVAL}

The abstract and thesis of Tanya Leigh Ostrogorsky for the Master of Science in psychology was presented on June 6,1997, and accepted by the thesis committee and the department.

COMMITTEE APPROVALS

Nancy Perrin, Chair

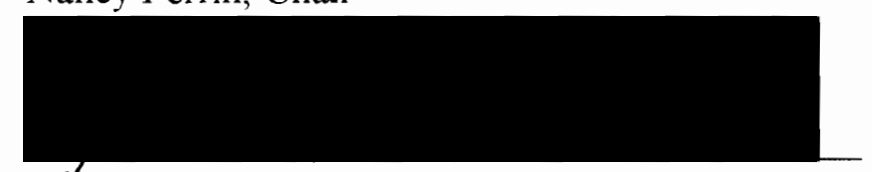

Joln Rueter

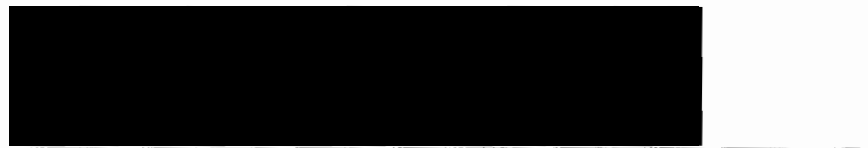

Gerald Guthrie

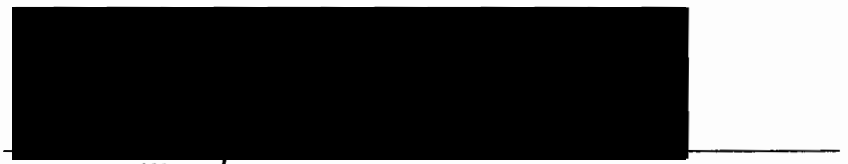

Tracy Dillon/

Representative of the Office of Graduate Studies

DEPARTMENT APPROVAI

Rogt Jenning, Chair

Department of Psycholog.
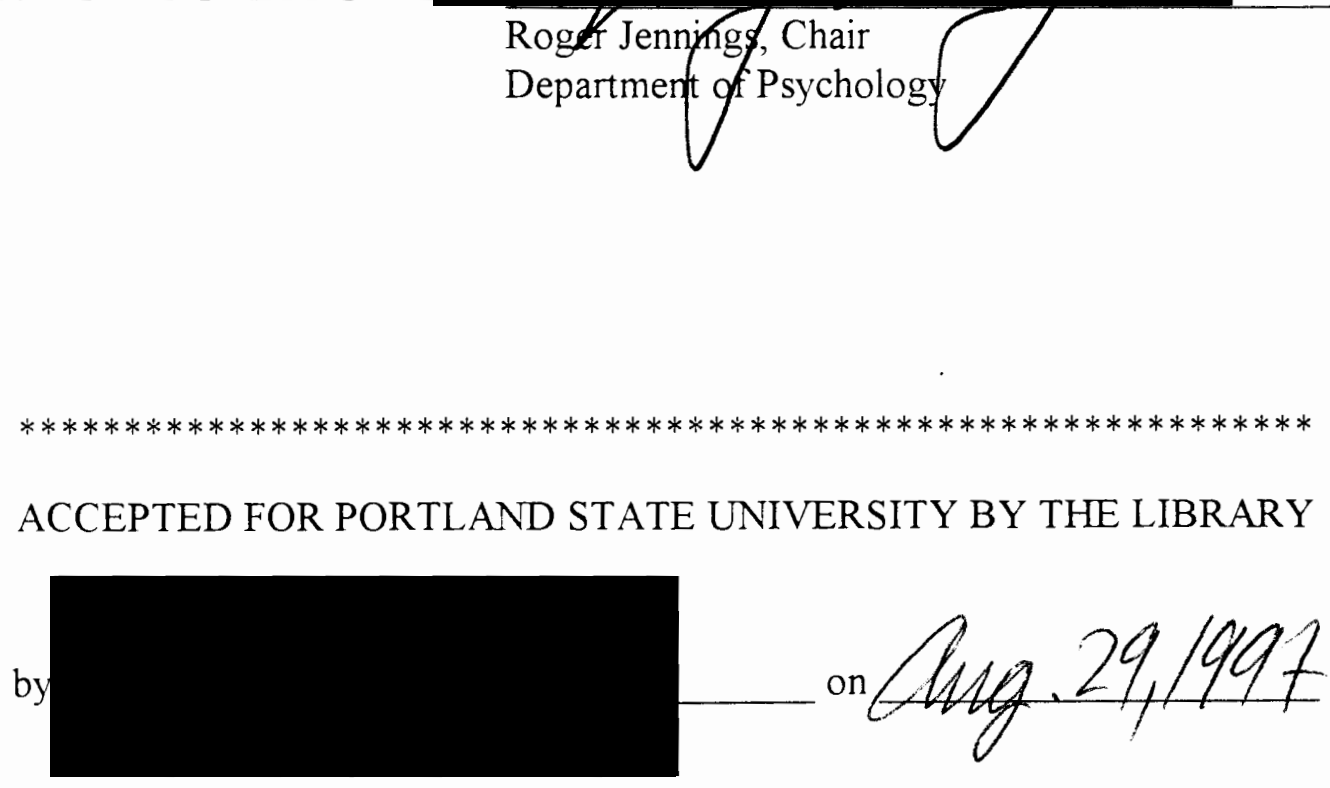


\begin{abstract}
An abstract of the thesis of Tanya Leigh Ostrogorsky for the Master of Science in Psychology presented June 6, 1997.
\end{abstract}

Title: Student Outcomes, Educational Technology, And Assessment In Large Classrooms: Effects On Planned Behavior

The purpose of this research was to investigate the impact of educational technology and classroom assessment on student outcomes. The research used a pretest post-test matched pairs design to test these effects. The Theory of Planned Behavior (TPB) was used as a foundation for the model tested. Differences between the model tested and the TPB include the addition of Perceived Behavioral ControlTime 2 (PBC), and the dropping of Subjective Norms from the model.

Participating faculty were trained in the use of educational technology, assessment, and course design. Each faculty taught two sections of a large course: first without the enhancements; and second with the enhancements. 483 participants had both Time 1 and Time 2 data; 235 in the control condition and 248 in the experimental condition.

Results found no statistically significant difference between the control and experimental conditions; however, interesting relationships existed within the model that warrant further research. Path coefficients indicated a negative relationship between PBC-Time 1 and the self-report Behavior measure. This suggests that for some students who report a high sense of control or high performance standard in a course do not report enjoying the class or working hard at homework. It was also found that the path from PBC-Time 1 to PBC-Time 2 was non-significant for the 
control condition. The significant path found in the experimental condition indicated that a high level of control at Time 1 was associated with a high level of control at Time 2. Suggesting that the use of assessment and technology in the classroom assists in maintaining a strong sense of personal control in a class over time. When using an objective measure of student performance, such as percentage correct on specific exam questions, the path from $\underline{\text { PBC-Time } 1}$ to percentage correct $\underline{\text { Behavior measure was }}$ non-significant for both conditions, indicating the confidence and a high performance standard early in a course are not indicators of success on exams. It was also found

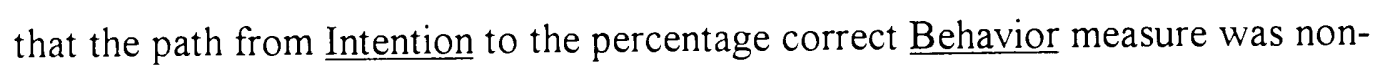
significant for the control condition. This path also reflected a low negative relationship between these two variables. 
STUDENT OUTCOMES, EDUCATIONAL TECHNOLOGY, AND ASSESSMENT IN LARGE CLASSROOMS: EFFECTS ON PLANNED BEHAVIOR

by

TANYA LEIGH OSTROGORSKY

A thesis submitted in partial fulfillment of the requirements for the degree of

MASTER OF SCIENCE

in

PSYCHOLOGY

Portland State University

1997 
List of Tables .iii

List of Figures. iv

Introduction 1

Technology and Higher Education................................................................ 2

Classroom Assessment and Higher Education................................................. 6

Theory of Reasoned Action and Theory of Planned Behavior ….......................... 8

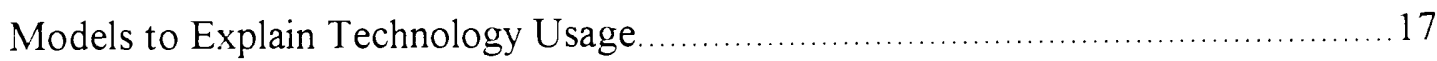

Methodological Issues in Educational Research .............................................21

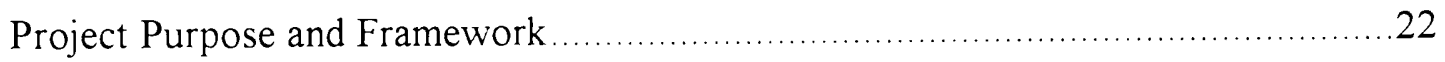

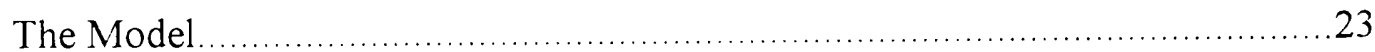

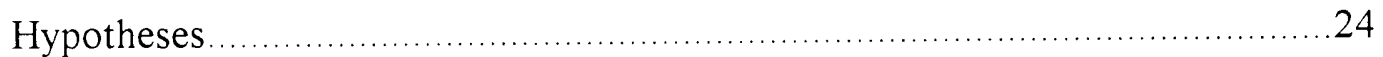

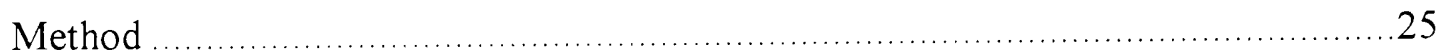

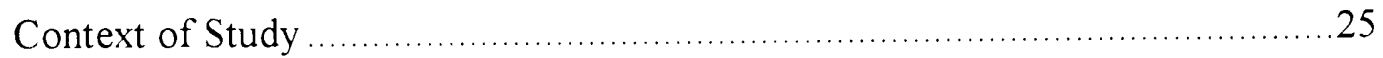

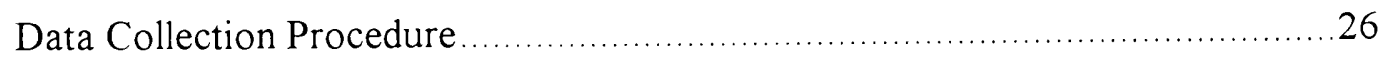

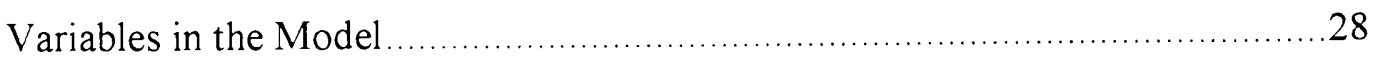

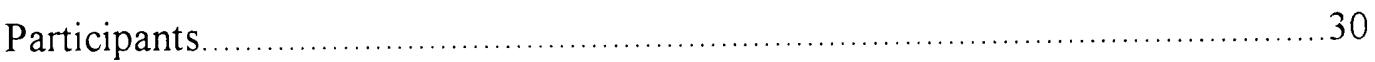

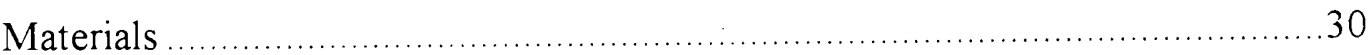

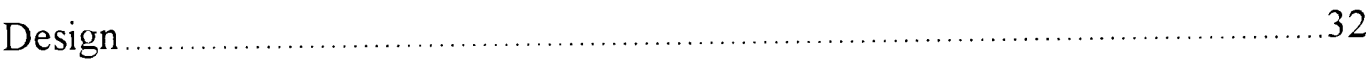

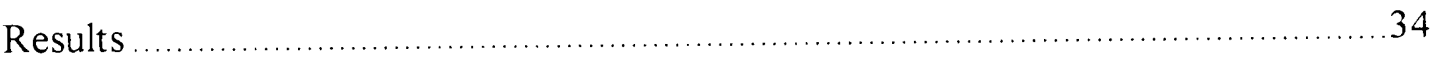

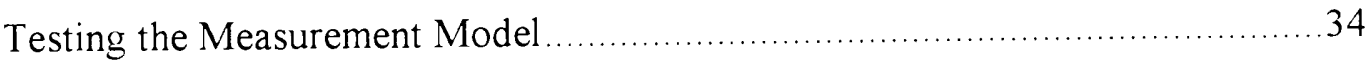

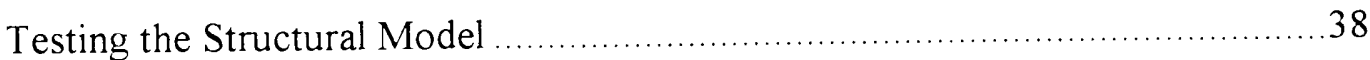

Model Comparison and Hypotheses Results.............................................42

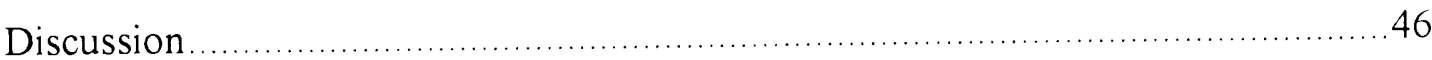


Behavior 1-Self Report Measures

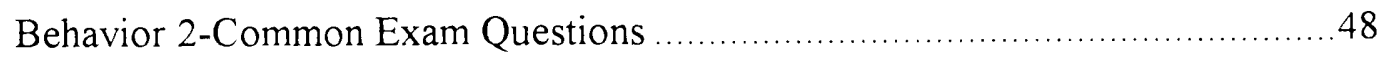

General Discussion ................................................................. 50

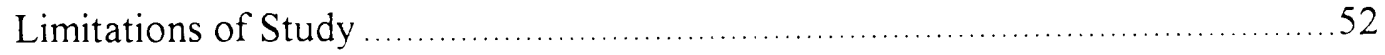

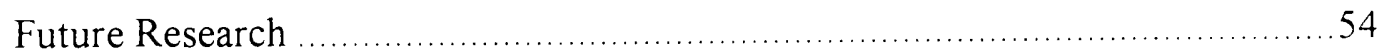

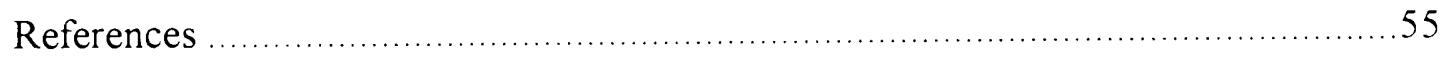

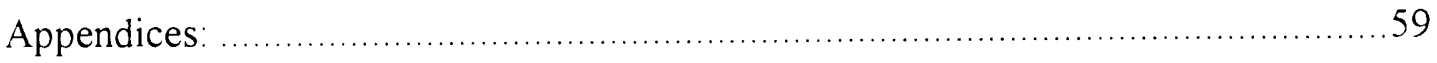

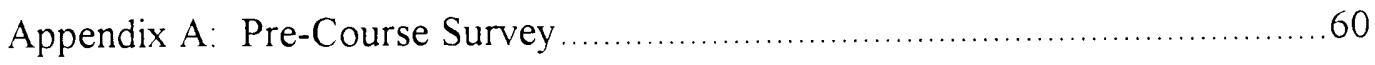

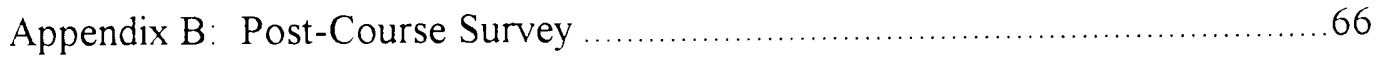




\section{List of Tables}

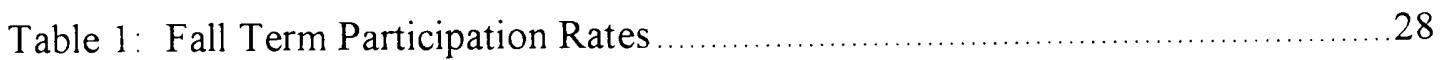

Table 2: Winter Term Participation Rates ............................................. 28

Table 3: Pre-Course Variables in the Model..............................................29

Table 4: Post-Course Variables in the Model .............................................29

Table 5: Exploratory Factor Analysis Factor Loadings for Behavior 1 ..................36

Table 6: Measurement Model Factor Loadings for Behavior 1 ...........................39

Table 7: Measurement Model Factor Loadings for Behavior 2 ........................ 40

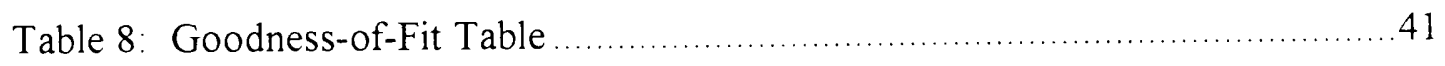




\section{List of Figures}

Figure 1: Theory of Reasoned Action ................................................. 9

Figure 2: Theory of Planned Behavior (Version 1 and Version 2) ........................ 13

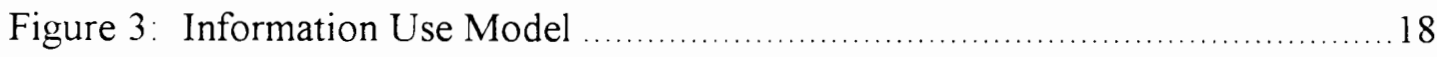

Figure 4: Technology Assessment Model .............................................. 18

Figure 5: Fitness of Purpose Model ................................................... 19

Figure 6: Theory of Planned Behaviour .............................................. 19

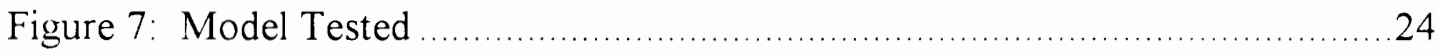

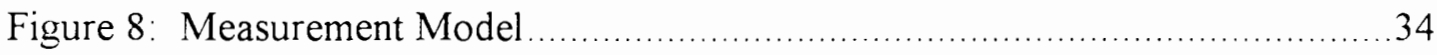

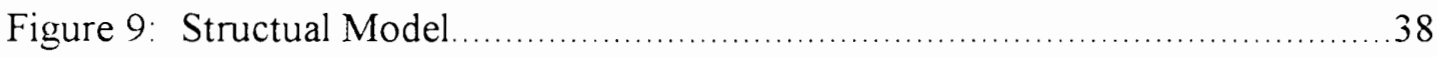

Figure 10: Control \& Experimental Condition Path Coefficients for Behavior 1 .....42

Figure 11: Control \& Experimental Condition Path Coefficients for Behaivor 2 ....43 
Student Outcomes, Educational Technology, and Assessment in Large Classrooms: Effects on Planned Behavior

\section{Introduction}

One core aspiration for psychologists is the ability to predict behavior; however, the complicated nature of humans makes this task very difficult. One basic theory of the antecedents of behavior is the Theory of Planned Behavior (TPB), which is "fundamentally motivational in nature" (Ajzen \& Madden, 1986, p. 454). The TPB incorporates into the model the many constructs that mediate behavior, such as peer influence and attitudes. It has been used successfully in many applied situations ranging from predicting women returning to work after childbirth (Granrose, 1984), to leisure activity choices (Ajzen \& Driver, 1992) to social responsibility (Ajzen, Timko, \& White, 1982)

One "behavior" of great interest to educators is student performance in the classroom. There are many components of the educational process that influence students' intentions to do well in a course as well as their actual performance. Two such components in higher education are the use of educational technology (Jacobson, 1994; Lamb, 1992; Smith \& Ely, 1994; Spotts, 1995) and the use of classroom assessment (Farmer, 1988; Astin, 1993; Angelo \& Cross, 1993). A clear understanding of how these factors effect students' intention to learn and subsequent performance could greatly aid educators, especially in the age of dwindling resources and increased scrutiny of public institutions. Therefore, this research will investigate the impact of educational technology and classroom assessment on student performance by proposing and testing a model of planned behavior. 


\section{Technology and Higher Education}

As mainstream computer use increases so does the integration of technology into educational learning environments, as evidence, Green (1996) found that $6 \%$ of courses surveyed accessed the Internet regularly to support instruction and 13\% regularly used Multimedia or CD-ROM based materials (p. 1-2). Additionally, Green reported $55 \%$ of the freshmen surveyed had previous experience with instructional technology (p. 1). Instructional technology is defined by Roth \& Sanders (1996) as "the broad concept of integrating various forms of technology into the teaching process" ( $p$. 22), another definition is, "the use of technology to achieve an instructional objective" (Spotts \& Bowman, 1995, p. 57). This increased application of technology to the educational environment shows that not only are faculty incorporating available technology tools, but students are familiar with the software and may be demanding the increased application in class. In sum, Green (1996) describes the use of technology in the classroom as a method to, "extend the content of the syllabus, enrich classroom discourse, promote communication among class participants, and enhance the learning opportunity" (p. 1).

What does technology enhanced mean? Roth \& Sanders (1996) cite Anderson and Cichoki (1992) in explaining this term and provide some illustrations. A general definition of technology enhanced, or media equipped, refers to a "centrally scheduled or departmentally scheduled teaching space with permanently installed media and classroom support technology designed to enhance the quality of teaching when properly utilized" (p. 24, emphasis added). However, with that definition any classroom that is assigned through the registrar's office and has a built-in slide projector would be considered technology enhanced. These are not the classrooms that are of interest in this project. This thesis focused on technology enhanced courses as opposed 
to classrooms that merely have technology available. For this thesis, a technology enhanced course is a course that has integrated one or more of the following into the course curriculum: e-mail, computer generated presentations (e.g., Power Point); computer generated graphics (e.g., Super Paint); live Internet searches; animation and simulations; discipline specific software as well as appropriate classroom assessment techniques.

An example of a technology enhanced classroom can be found at the College of Education at Western Illinois University. Their GTE Electronic Classroom contains, "a Macintosh IIci microcomputer, a 386 MS-DOS microcomputer, CD-ROM drive, Syquest drive, a videotape player, a videodisc player, a $35 \mathrm{~mm}$ slide projector, and a satellite input/output feed... all controlled through a touch screen from a Creston audiovideo-computer podium" (Roth \& Sanders, 1996, p. 25). University of Notre Dame has taken this idea and expanded the breadth with an 84 classroom building that has each room, "equipped with an innovative system for delivering instruction" (p. 25). This system is a centralized computer system in which faculty input their visual aids prior to class and then recall the images using a control panel in each class

Portland State University has blended these approaches in the creation of Harrison Hall--a single classroom that can hold 320 students. Harrison Hall was specifically designed for the integration of technology in the classroom. It houses a Power Macintosh 9500, an Orange Micro 486I PC, video cassette player and recorder, video disc player, closed circuit TV receiver, Wolfvision Visualizer (a camera that can project images of pages of three dimensional objects), Navitar Videomate 2100 (a slide to video transfer system), CD player, and dual well cassette recorder. All of which is projected on three nine by twelve foot rear projection screens at the front of the room. Images can be projected to one screen or to all screens, allowing up to three separate 
images to be projected at one time. There are also portable microphones as well as auditory assistance devices available. Additionally, these systems are fully integrated into the computer network to allow for live Internet searches and access to the World Wide Web as well as e-mail and communication systems. More detailed information on Harrison Hall can be accessed at http: $\| w w w$ icc.pdx. edu.

Portland State University also has two traditional classrooms that have been converted to technology enhanced classrooms where presentation materials are managed by the instructor from a podium. These rooms are less advanced, but all contain video and slide projectors, Elmo (a 3D object camera), and computer network connections and audio systems. Additionally, Portland State has portable computer systems that are set up on carts and are available for faculty to check out. These portable systems allow faculty to use instructional technology whenever desired.

One very important aspect that is linked to the success of ventures like Harrison Hall is student access to software modeled in classes. To assist in overcoming this obstacle Portland State allows each student a free e-mail address, has upgraded student computer labs to contain software programs being demonstrated in class (e.g., Netscape, Inspiration, Stella) as well as increased the number of computers available for student use outside class.

The integration of technology into the classroom curriculum not only allows for more effective presentation of materials but allows students the opportunity to interact with individuals that are out of regional contact or conveniently explore areas of interest that were previously difficult to access or completely inaccessible. For example, at University of Illinois, students can use a laser disc to perform chemistry experiments that would otherwise be dangerous or expensive. At Stanford University, an interactive computer simulation, "The Would-Be Gentleman," allows students to 
take the role of a French bourgeois and make decisions in Louis XIV's France about marriages, investments and such. At Iowa State University, dental students work on virtual patients before drilling on real teeth, and at University of Michigan, students can work on self paced tutorials to prepare for exams (Roth \& Sanders, 1996, p. 27-29). On Portland State University's campus, students can take biology tutorials on line or connect to faculty web pages to get assignments or check grades. Some faculty use the technology available in Harrison Hall to help students visualize molecules or watch video clips of child behavior. Other examples include live Internet searches for answers to students' questions or response to student e-mail about previous lectures.

While the integration of technology into the curriculum may have benefits there are two distinct drawbacks. The first is the capital investment required to have facilities dedicated to instructional technology. For example, Harrison Hall cost 3.2 million dollars. The second is the obsolesce of hardware and software purchased by the institution. Green (1996) reports, "the useful life of the desktop computer and accompanying software is a known factor, roughly 15 months for many core software applications and maybe 30-36 months for hardware" (p. 4). Green also found that only $22 \%$ of institutions surveyed had long-range financial plans for acquiring and retiring technology. Of note, Portland State University does have a plan; however, there is no funding for the implementation of the plan. Similarly, Kozma \& Johnston (1991) reported that technology will cost an institution $\$ 1000$ per student per year to keep technology based classrooms up to date and remodel traditional classrooms to incorporate technology. Green (1996) reported that $44 \%$ of public four-year colleges and $16.7 \%$ of private four-year colleges pass on this cost to their students in the form of a 'tech fee'. Portland State University currently charges students a $\$ 25$ per term technology fee. Considering Kozma \& Johnson's technology maintenance estimate, of 
$\$ 1000$ per student per year, it appears as if Portland State will be unable to sustain technology purchased nor upgrade as needed. Subsequently, this lack of long term financial support will have a serious impact on the effectiveness of the technology once current technology is considered obsolete.

Considering the large financial commitment needed to maintain technology on campuses these expenditures cannot be justified without supporting evidence on the effectiveness of technology in improving student outcomes. Therefore, the important questions are: Does the integration of technology make a difference in student learning? Does the massive investment produce better students who perform at a higher level than students trained in non-technology enhanced classrooms?

\section{Classroom Assessment in Higher Education}

Farmer, D. W. (1988), stated, "Assessment as learning is a faculty-driven diagnostic and formative evaluation process aimed at improving student learning by providing continual feedback on academic performance to individual students" (p. 150) and this assessment is different that assessment for measuring. He states that, "Assessment viewed as measuring is an administratively-driven, standardized, and summative evaluation process designed to produce a numerical rating" (p.150). The type of assessment that is addressed in this thesis is the assessment as learning process

There are a variety of strategies to implementing assessment. Some examples included summer advisement or orientation periods, standardized assessment, alumni surveys, or course embedded assessments. The faculty in this study used the courseembedded assessment model. This model, "focuses on assessing students as part of the natural teaching/learning process in the classroom and on providing documentation of cumulative learning" (Farmer, 1988, p. 155). 
Angelo \& Cross' (1993) have detailed the concept of classroom assessment and have also gathered multiple techniques to assist faculty members with the integration of assessment into a course's curriculum. In detailing the concept of classroom assessment, Angelo \& Cross specifically state that the purpose of classroom assessment is "to empower both teachers and their students to improve the quality of learning in the classroom" (p. 4)

The authors provide the following example to illustrate why teachers need to use classroom assessment in their courses. "If a teacher's goal is to help students learn points $A$ through $Z$ during the course, then that teacher needs first to know whether all students are really starting at point A and, as the course proceeds, whether they have reached intermediate points B, G, L, R, W, and so on" (Angelo \& Cross, 1993, p. 4-5) By checking the status of the learning process at intermediate points in the course, not just at the mid-point and final point, students and teachers receive timely feedback. This feedback allows teachers to make course corrections as needed and provides students frequent checks to ensure they are learning and integrating the material at the cognitive level needed to succeed in the course.

As with many issues within the educational arena, how classroom assessment is implemented influences overall effectiveness. There are seven characteristics of classroom assessment that ensure assessment is beneficial for both students and teachers (Angelo \& Cross, 1993). They include being learner-centered, teacherdirected, mutually beneficial, formative, context-specific, ongoing, and rooted in good practice. Learner-centered means that the primary focus of assessment is on the observation and improvement of learning, not teaching. Teacher-directed means that the teacher decides what is to be assessed and what will be done with the results of the assessments. Mutually beneficial means that both the teacher and student gain 
knowledge or insight from the assessment activity. Formative refers to the role assessment plays in the classroom. Assessment is said to be formative because its purpose is to improve the quality of teaching and learning, not to provide evidence of such. Context-specific means that what works in one course may not work in another. This means that in order for assessment to be effective the faculty member must already have good teaching practices. The integration of CAT's into a course will not make the course successful if the instructor in unprepared or unqualified to teach the course

Additionally, the integration of assessment into the classroom provides students with a higher sense of control over their personal performance in the course. For example, if a teacher only gives a mid-term and a final, the level of feedback to the student in very low and may be received too late to request changes in content presentation or study habits. With ongoing assessment the student can receive feedback on their performance and make adjustments as they see fit.

Theory of Reasoned Action \& Theory of Planned Behavior

Theory of Reasoned Action (TRA) was the product of frustration from trying to predict behavior with measures such as Likert scales, and semantic differential scales that were commonly relied upon in the late nineteen-sixties (Terry, et. al., 1993). The following discourse outlines the TRA and explains how the it evolved into the Theory of Planned Behavior (TPB). Figure 1 illustrates the TRA and Figure 2 illustrates TPB 
Figure 1

Theory of Reasoned Action

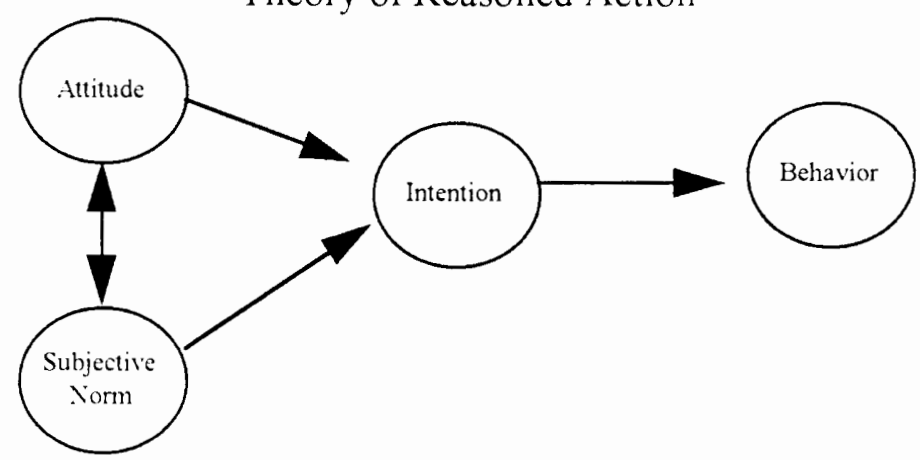

The TRA states that, "the immediate antecedent of any behavior is the intention to perform the behavior in question" (italics in original, Ajzen \& Madden, 1986, p. 454). This model assumes, as Intention increases so does the likelihood of the related behavior occurring. The TRA incorporates two factors as independent determinants of Intention. Ajzen \& Madden (1986) refer to these factors as a personal factor and a social factor. The personal factor is the Attitude Toward the Behavior (Attitude) and the social factor is referred to as Subjective Norms (SN). In this model, Attitude refers to the degree to which a person has a favorable or unfavorable evaluation of the behavior in question. $\underline{\mathrm{SN}}$ refers to the influential power of other individuals or groups to mediate the performance of the behavior. Additionally, Intention refers to the plan to perform a behavior and Behavior is the evidence of that intention (p. 454). In general, the TRA states that as attitudes become more favorable and subjective norms more positive toward a behavior, peoples' intention to do the behavior becomes stronger followed by an increase in the actual behavior.

The TRA also addresses the antecedents of Attitude and Subjective Norms Ajzen \& Madden (1986) proposed that two distinct types of beliefs serve as 
antecedents to the factors: behavioral beliefs and normative beliefs. Behavioral beliefs influence Attitude toward the behavior and, each behavioral belief links the behavior to a certain outcome, or to some other attribute such as the cost incurred by performing the behavior. The outcome's subjective value then contributes to the attitude toward the behavior in direct proportion to the strength of the belief (p. 454-455).

Normative beliefs make up the underlying determinants of $\underline{\mathrm{SN}}$ and refer to the influence that other groups or individuals have on the individual regarding the performance or non-performance of a behavior. When measuring Attitude and $\underline{\mathrm{SN}}$, Ajzen \& Madden (1986) conceive of these variables as a combination of factors. Attitude is the sum of the outcome beliefs weighted by importance and Subjective Norms is the sum of the normative beliefs weighted by the motivation to comply.

The behavioral and normative beliefs provide the building blocks for the application of the model. For example, to measure student attitudes towards the Internet, the extent to which the student believes that using the Internet will improve their performance in a class (the behavior) is weighted by the importance of performing well to the individual.

The TRA has been successfully used in the past when applied to the theory of self-monitoring (Ajzen, Timko, \& White, 1982). The theory of self-monitoring is summed up by Snyder and Gangestead (1986):

"According to theoretical analyses of self-monitoring, people differ in the extent to which they can and do observe and control their expressive behavior and self-presentation. Individuals high in self-monitoring are thought to regulate their expressive self-presentation for the sake of desired public appearances, and thus be highly responsive to social and interpersonal cues of situationally 
appropriate performances. Individuals low in self-monitoring are thought to lack either the ability or the motivation to so regulate their expressive selfpresentations. Their expressive behaviors, instead, are thought to functionally reflect their own enduring and momentary inner states, including their attitudes, traits, and feelings" (p. 125)

In summary, high self-monitors regulate their behavior to be situationally appropriate by reading social cues. On the other hand, low self-monitors self presentation is consistent in different situations, they do not adjust their behavior depending on the environment they are in.

In Ajzen, Timko, \& White's (1982) study, 155 college students participated in a study investigating social responsibility, marijuana smoking, voting behavior, and political beliefs. The TRA accounted for $27 \%$ of the variance in intention to vote and $64 \%$ of the variance in intentions to smoke marijuana. Even though the TRA was successful in some applied situations, Ajzen \& Madden (1986) expressed concern over using verbal responses about intention to predict behavior. The authors explain by saying,

the measure of intention must correspond in its level of generality to the behavioral criterion; the intention must have remained constant between the time of assessment and the time the behavior is observed; and thirdly, the behavior must be completely under the individual's control. (emphasis in original, p. 455)

The most important of these three problems is the issue of absolute control over the behavior, since complete control was defined as being able to decide at will to perform the behavior or not perform the behavior. For example, a student may have every intention of studying nightly for a course, but a chronically ill baby-sitter may interfere 
with that intention by not showing up. Therefore, the intention to study may be overwhelmed by child care responsibilities.

In regards to the completeness of this model, Terry et. al., (1993) stated that one common criticism of TRA is that, 'additional variables should be considered' ( $\mathrm{p}$. $\mathrm{xxi}$ ). However, his response to the criticism of the simplicity of the model is: one of the main reasons for the theory's longevity (in addition to the fact that it does often explain a considerable and statistically significant amount of variance in intentions and behaviors), is the fact that it is comprised of a relatively small set of theoretically interrelated concepts, each of which has been operationally defined (p. xxi).

He further states, that before adding more variables to the model, a researcher should first evaluate the measurement variables for reliability and validity and then consider adding latent variables when theoretically appropriate.

The TRA relies on Intention as the predictor of Behavior; however, this will be inadequate when complete control over the behavior is absent. Therefore, Ajzen \& Madden (1986) proposed a complete model--the Theory of Planned Behavior (TPB). The TPB incorporates, "some estimate of the extent to which the individual is capable of exercising control over the behavior in question" (p. 456). This behavioral control factor was termed Perceived Behavioral Control (PBC) and is defined as the person's belief as to how easy or difficult performance of the behavior is likely to be (p. 457). This perception of how easy or difficult the behavior would be is not only based on previous personal experience, but incorporates the experiences of other individuals Like Attitude and Subjective Norms, $\underline{\text { PBC }}$ is determined by summing the control beliefs, or measurements of $\underline{\mathrm{PBC}}$, weighted by the importance of the behavior to the individual. One issue to note regarding the relationship between $\underline{\mathrm{PBC}}$ and Attitude is 
that considering the above definition, $\underline{\mathrm{PBC}}$ could be viewed as an affective evaluation of Attitude. Therefore, when Attitude measures include affective and evaluative scales, $\underline{\mathrm{PBC}}$ may not significantly improve prediction

Figure 2

Theory of Planned Behavior

Version 1 (Without Broken Arrow) \& Version 2 (With Broken Arrow)

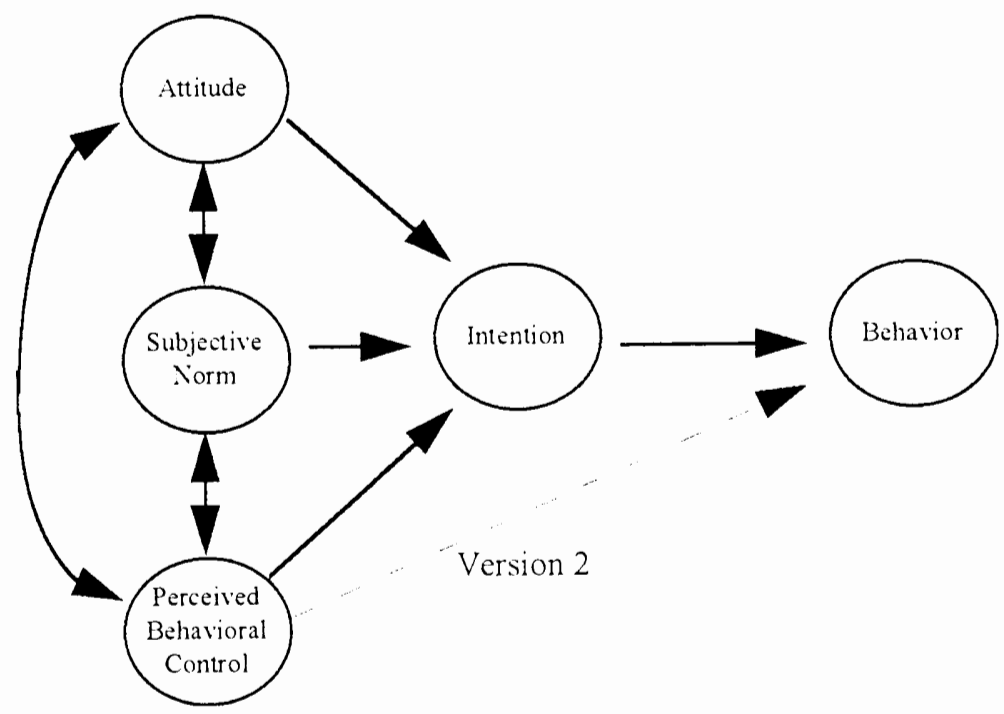

Like TRA, TPB says that as Attitudes become more favorable and $\underline{\mathrm{SN}}$ more positive toward the Behavior, Intention to perform the behavior increase. In addition as people feel they have more control over the behavior, their intention to perform the behavior increases. Ajzen \& Madden (1986) proposed two possible versions of the relationship between $\underline{\mathrm{PBC}}$ and Behavior. Version 1 maintained that $\underline{\mathrm{PBC}}$ was only a motivational factor of Intention. This means that $\underline{\mathrm{PBC}}$ effects Behavior only through Intention. Therefore, if an individual believes that they are unable to perform a behavior or does not possess the required skills to complete the behavior then a 
positive attitude toward the behavior and referent group support for the behavior may not be enough not to spur the intention of a behavior. This version assumes complete mediation of $\underline{\mathrm{PBC}}$ through Intention that then predicts Behavior (p. 457-458).

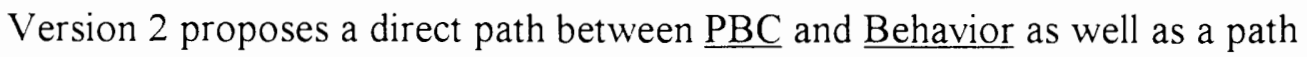
mediated by Intention. The inclusion of this direct path suggests that perceived control of a behavior can be a partial substitution for actual control over a behavior. This suggestion is very important to understand. The inclusion of a direct path from $\underline{P B C}$ to Behavior reflects a substitution for a measure of actual control while the mediated path represents the perception of control. The following example illustrates the difference between the concept of actual control and perception of control. A student's attitude towards nightly studying is positive (attitude), and that student's referent group supports nightly studying (subjective norms), and the student also believes that he/she can achieve nightly studying (PBC); therefore, that student intends to study every night (intention). This is the mediated path from $\mathrm{PBC}$ to Intention. However, during the term, the student's baby-sitter cancels due to illness. This cancellation by the babysitter was not under the actual control of the student, but would directly effect the overall behavior (nightly studying). This is the direct path from $\underline{P B C}$ to $\underline{\text { Behavior. }}$

One important note about Version 2 of the model is that a strong path coefficient from $\underline{P B C}$ to $\underline{B e h a v i o r}$ will be seen only if two conditions are met. First, the behavior must not be under complete volitional control, and second, PBC must parallel actual control to a certain degree (Ajzen \& Madden, 1986, p. 459-460)

To test the two versions, Ajzen \& Madden (1986) first tested Version 1 of the TPB by studying lecture attendance. 169 undergraduate psychology students were asked to complete a questionnaire measuring $\underline{\text { Attitude }}, \underline{\mathrm{SN}}$, and $\underline{\text { Intention towards }}$ attending class lectures. Attendance was taken eight times prior to the administration 
of the survey and eight times after completion of the survey. Attitudes were measured with eleven outcome items such as 'My attending this class every session will result in my missing a lot of sleep' or 'By missing class I will fall behind in my studying for this class.' These attitude items were paired with a belief strength item and then the belief strength item was multiplied by the corresponding outcome item. These products were then summed and provided the measure of attitude toward attending class lectures. $\underline{\mathrm{SN}}$ was measured similarly by asking about five referents (e.g., parents, instructors, friends) and their expectation about class attendance. To get the belief-based measurement of $\underline{\mathrm{SN}}$, items were paired to have both a belief statement and a motivation to comply with referent statement. These items were multiplied and then summed across to make up the subjective norm measure. $\underline{\mathrm{PBC}}$ items asked students to rate a list of ten reasons why they might not attend lectures, as well as answer direct questions about class attendance (e.g., How much control do you have over whether you do or do not attend this class every session; If I wanted to I could easily attend this class every session). Intentions were measured with items such as, 'I will try to attend this class every session' or 'I intend to attend this class every session.' The Behavior measure was the 16 attendance rosters

Ajzen \& Madden (1986) found that the addition of PBC to the model increased the total multiple correlation from .55 to .68 . However, during hierarchical regression analysis it was found that the regression coefficient between $\underline{\mathrm{PBC}}$ and $\underline{\text { Behavior was }}$ non-significant. Additionally, the correlation between Intention and Behavior was 36 and the addition of $\mathrm{PBC}$ to the equation only resulted in a multiple correlation of 37 , an increase of 01 . Therefore, this data provides little support for the direct link between $\mathrm{PBC}$ and Behavior; however, the behavior being tested here is one that is under volitional control and the authors previously stated that link would not be 
significant unless the behavior of investigation was only partially under volitional control.

To test Version 2 of TPB, Ajzen \& Madden (1986) selected getting an 'A' in a course as the target behavior. This was selected considering the results from testing Version 1. This target behavior is a behavior that is not completely under volitional control. The factors were measured by pairing belief based items with importance of behavior items as done in testing version one of this theory. Ninety-nine upper division business administration students participated in the testing of this version of the theory by responding to a survey asking them about their attitude towards, influence by others, and perceived control over getting an ' $\mathrm{A}$ ' in the course, in a longitudinal design Participants were also asked about past grades, overall GPA, and to predict their grade in that class. The analysis of this data was broken into two sets. The first set addressed the prediction of intentions (Wave I) and the second set addressed the prediction of behavior (Wave II). These will be addressed in that order.

Regarding the prediction of intentions (Wave I), Step 1 of a hierarchical

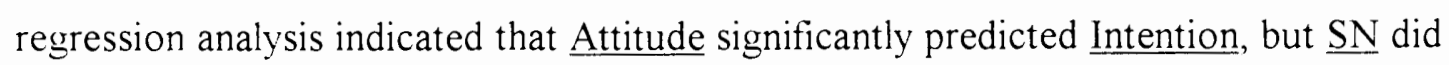
not significantly improve prediction of intentions. This step tested the TRA since it only included Attitudes and Subjective Norms as the latent variables. Step 2 in the prediction of Intention tested the TPB with the three determinants previously discussed. Results indicated that the inclusion of $\mathrm{PBC}$ to the model increased the prediction of intentions from 45 to $.65\left(\mathrm{~F}_{3,86}=29.40, \mathrm{p} .<.01\right)$. Ajzen \& Madden (1986) also found that this increase was additive since Step 3 of the analysis introduced the interaction terms (PBC X Attitudes; PBC X SN) which failed to improve prediction 
Wave II of this analysis found the paths to Behavior from $\underline{\mathrm{SN}}$ had remained constant over time, while the paths from Attitudes, $\underline{\mathrm{PBC}}$, and Intention to Behavior had been significantly lowered. Even so, the between wave correlation remained stable at, $.61, .56, .57$, and .51 , respectively. Results also indicated that the correlation between attained grades and intentions was .39 , this increased to .45 with the addition of $\mathrm{PBC}$ to the model $\left(\mathrm{F}_{2.87}=11.10, \mathrm{p}<.01\right)$. This effect was maintained after controlling for past grades. In sum, $\underline{P B C}$ significantly increased prediction independent of other latent variables and prior academic performance. These findings supports Version 2 of the model where $\underline{\mathrm{PBC}}$ is not mediated by Intention and also provides support for the model being tested here

\section{Models to Explain Technology Usage}

Klobas (1995) provides further support for the TPB is her study investigating the use of electronic information resources (e.g., Internet, CD-ROM,). The models tested included: 1) Information Use Model; 2) Technology Assessment Model; 3) Fitness of Purpose Model; and 4) Theory of Planned Behavior. Refer to Figures 3 through 6 for schematics of models.

The following description outlines the four models tested and clarifies the constructs that are incorporated into the models. The Information Use Model has two determinants of Information Use: Quality and Accessibility. Quality referred to the quality of the information, technical quality, and relevance. Accessibility measures ease of use physical access, and intellectual access. 
Figure 3

Information Use Model

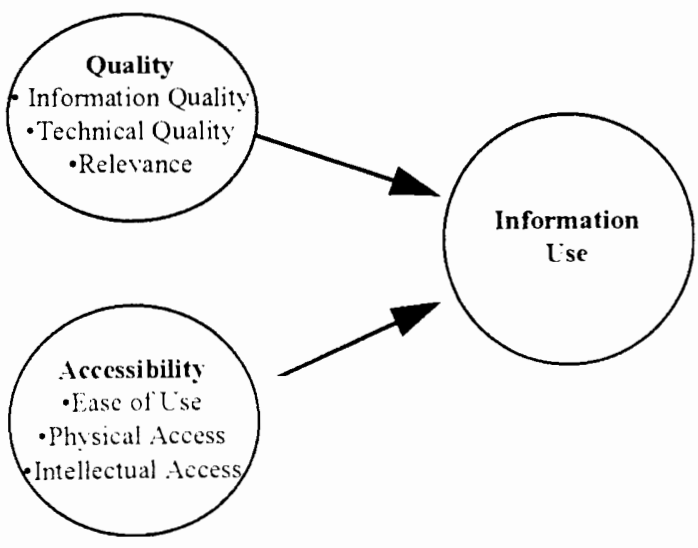

The Technology Assessment Model also has two determinants of Information Technology Use: Perceived Usefulness and Perceived Ease of Use. Perceived Usefulness measures work performance, work quality, work ease and work control; while Perceived Ease of Use measures ease of use, interface, and ease of learning.

Figure 4

Technology Assessment Model

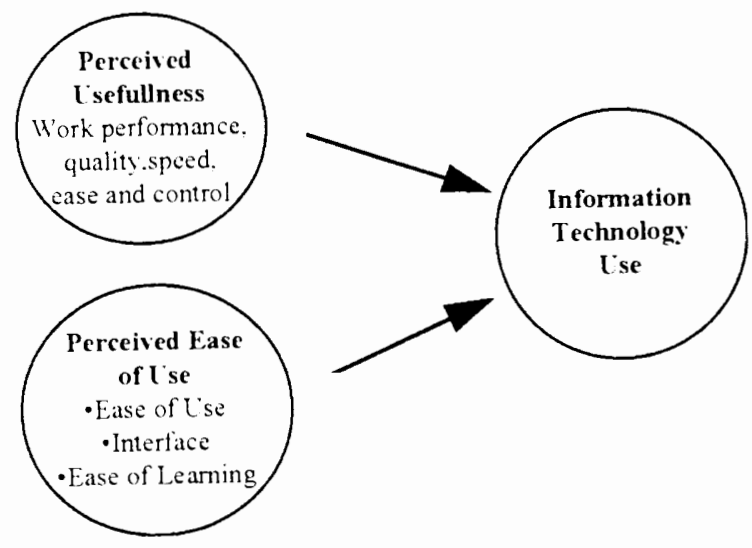


The Fitness of Purpose model is a combination of the two aforementioned models. The determinants of Electronic Information Resource Use are Perceived Usefulness and Perceived Accessibility. The Usefulness construct measures the expectation that information technology will improve work, while the Accessibility construct measures the degree to which the information resources will be used, or not used. The final model tested was the Theory of Planned Behavior.

Figure 5

Fitness of Purpose Model

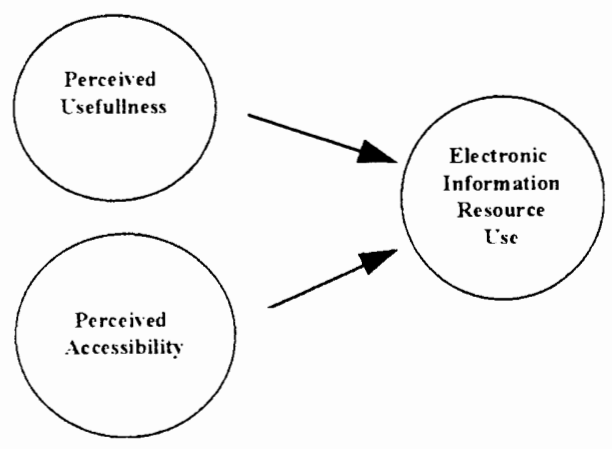

Figure 6

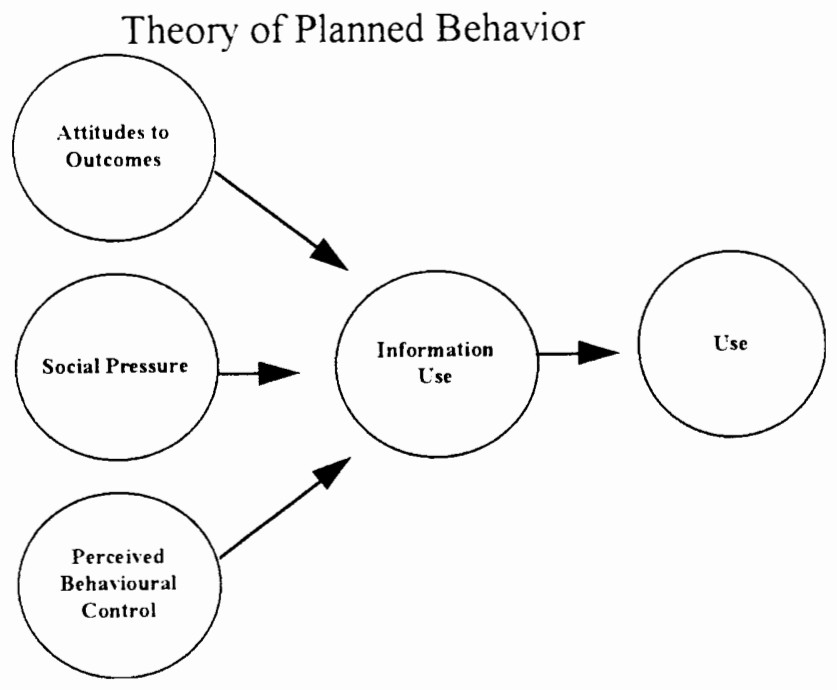


To test these models, Klobas (1995) studied three Australian universities that had developed campus wide information systems (CWIS). These CWIS were developed to easily disseminate information and provide basic access to the Internet For all the universities studied, any individual hooked up to the university LAN or server could access the information on the CWIS. The three universities include in this study were all considered traditional even though they varied in size, geographical area, and academic specialty, 1,122 surveys were distributed to a variety of faculty and staff resulting in 299 completed surveys being returned. The survey used a seven-point Likert scale anchored only at the ends. Items measured intention to use CWIS during the next month, quality, ease of use, accessibility, and usefulness of the CWIS, normative beliefs for CWIS use, social pressure to use CWIS; attitudes and expected outcomes of CWIS use, and perceived control over CWIS use

Results indicated that the Information Use Model accounted for the least amount of variance, $33 \%$ of all the models tested. The Goodness-of-Fit (GFI) was . 80 , but the Adjusted Goodness-of-Fit (AGFI) was 65 with a Root Mean Square Residual (RSMR) of .15. The Fitness of Purpose Model explained $55 \%$ of the variance in the data, with a GFI of 85 and an AGFI of .76, the RMSR was .13. Although this model was a relatively good fit for the data, analysis of the residual data indicates that additional factors would improve the model. The Technology Assessment Model accounted for $67 \%$ of the variance; however the GFI was . 73 , the AGFI was .59, and the RMSR for this model was .06. Considering the goodness of fit indices cited here, all models were rejected except the TPB

Results indicated that the TPB explained $76 \%$ of the variance on information use, and was the best model of the four with an GFI of .95, AGFI of .91, and a RMSR 
of .04. Additionally, all the residuals were randomly distributed. As stated by Klobas, the superior performance of the TPB "suggests that information resource use is motivated by similar factors to other human behaviours" (spelling in original, p. 112) In sum, "electronic information resource use is an example of that set of human behaviours influenced by a person's attitudes to outcomes, motivation to please others by performing the behaviour, and perception that they have control over the behaviour" (Klobas, 1995, p. 112). Considering these results and research questions posed here, the TPB is an appropriate foundation for the model of student outcomes and educational technology tested in this study.

\section{Methodological Issues in Educational Technology}

Clark (1996) has been critical of studies comparing courses taught with technology with courses taught without technology. The studies that he targeted are in the area of computer based instruction (CBI). $\mathrm{CBI}$ is an instructional technique in which instruction is moved out of the traditional classroom onto the computer. In a replication study, Clark found, "that achievement gains found in these CBI studies are overestimated and are actually due to the uncontrolled but robust instructional methods embedded in CBI treatments" (p. 249). Clark further criticized the comparison of CBI courses with traditional courses because he found that "effect size reduce[d] to insignificant levels when the same teacher designs both the $\mathrm{CBI}$ and the traditional treatments" (p. 250). Clark also alludes to the possibility of sabotage by faculty in CBI courses; however, Clark does admit that when comparing courses for effect that the use of a same-teacher design allows for greater control over instructional style and content (p. 251) 
In this project, computers are not replacing faculty members, but enhancing the traditional lecture format. Technology may provide faculty with a platform to improve their instructional methods and many of the changes in instructional methods may only be accomplished with the aid of technology. Sabotage should not be of great concern in this study since the faculty will not be replaced by the technology. Another issue brought up by Clark is that new instructional approaches in CBI can diffuse over to traditional courses. However, in the design selected here all control courses were being taught first followed by the experimental conditions. Therefore, this design minimized the diffusion from each condition.

\section{Project Purpose and Framework}

The literature has addressed models to explain student attendance (Ajzen \& Madden, 1986) as well as technology use by faculty and staff (Klobas, 1995); however, no literature was found on the effect of technology enhanced courses on student outcomes. This project attempted to bridge this gap by proposing and testing a model to predict student outcomes. This model of student outcomes compares enhanced and non-enhanced courses. As stated previously, an enhanced course is a course that has integrated one or more of the following into the course curriculum: e-mail, computer generated presentations (e.g., Power Point); computer generated graphics (e.g., Super Paint); live Internet searches; animations and simulations; and discipline specific software as well as classroom assessment techniques. It was hypothesized that the certain paths in the model will be stronger for the enhanced courses than non-enhanced courses 


\section{The Model}

Figure 7 presents the model that draws on elements of TPB and other literature (Kiwala, 1993; Manstead, et. al., 1983; Smetana \& Adler, 1980). In this model, the

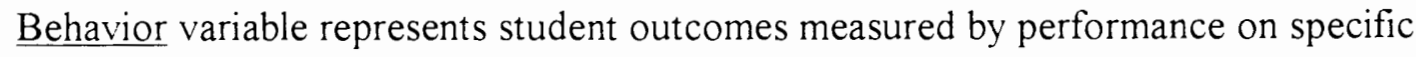
exam questions, and post-course self reports. Behavior is influenced by Intention and $\underline{P B C}$ that is measured twice: $\mathrm{PBC}-$ Time 1 ; and $\mathrm{PBC}$-Time 2. The model states that

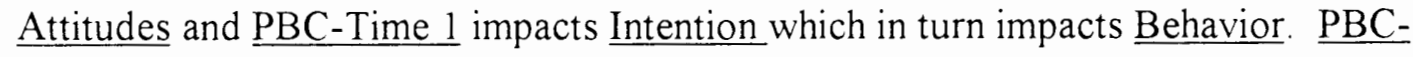

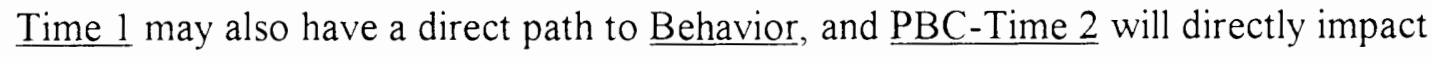
Behavior. Please note, Subjective Norms which is a major component of TPB is not included in this model because the data set used to test the model did not incorporate a measure of Subjective Norms.

When considering the role of educational technology and assessment in this model, assessment and educational technology should strengthen the connection between Intention and Behavior and the connection between $\underline{\mathrm{PBC}-\mathrm{Time} 2}$ and Behavior. Educational technology and assessment should act as enablers in the learning process allowing students to carry through on their intentions. Assessment provides feedback to the student on their performance in the class. This feedback should help the student revise their estimate of control and make the relationship between $\underline{\mathrm{PBC}-\mathrm{Time} 2}$ and Behavior stronger than the relationship between PBC-Time 1 and Behavior

Please note that Attitude, $\underline{\mathrm{PBC}-\text { Time } 1}$, and Intention were all collected at Time 1. Figure 7 uses directional arrows to indicate the hypothesized relationship among these variables; however, since these variables were all Time 1 data the analysis only test the association of these variables 
Figure 7

Model Tested

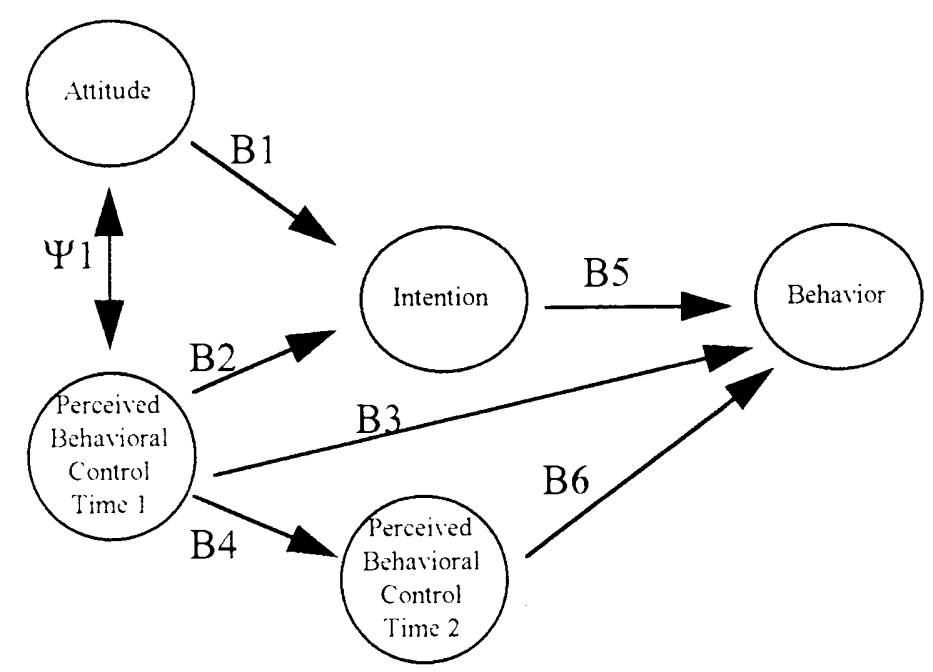

Hypotheses

Hypothesis \#1: The influence of PBC-Time 1 on Behavior (B3) will be stronger for the technology and assessment enhanced courses than the non-enhanced courses

Hypothesis \#2: The intention to behavior influence (B5) will be stronger for enhanced courses than non-enhanced courses.

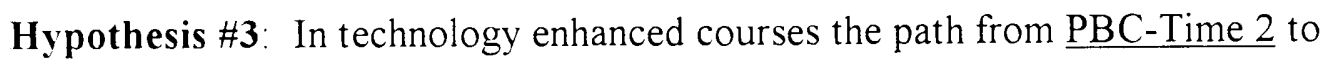
Behavior (B6) will be stronger than the path from $\underline{\mathrm{PBC}-T i m e} 1$ to Behavior (B3). 


\section{Method}

\section{Context of Study}

Since this thesis was a subset of a large grant based project that was already underway when the research proposal was written, the analysis here was considered a secondary data analysis. The data came from a federally funded project sponsored by the United State's Department of Education's Fund to Improve Post-Secondary Education (FIPSE). Nineteen Portland State University faculty volunteered to participate in the study. In preparation for the project, 14 faculty members enrolled in a Summer Workshop that provided course design, technology training, and assessment training. The faculty that participated in the Summer Workshop taught technology and assessment enhanced courses.

This project was designed to improve student experiences in large classrooms, establish an infrastructure for technology implementation, provide faculty and curriculum development support, and evaluate the effectiveness of educational technology on student outcomes and cost efficiency

Faculty will participate in the project for two years. In the first year, they integrated multimedia and e-mail into their courses. In the second year, out-of-class tutorials and pre-enrollment self-administered quizzes will be integrated in the courses. Pre-enrollment quizzes are computer based quizzes that students can take anonymously over the Internet. These quizzes will allow students to determine their knowledge of prerequisite material, and locate references for weak areas. The project was designed so that any electronic media developed during the first year of the project can be easily transferred into second year tutorials and quizzes. By using a longitudinal approach to the implementation of technology, the effects of different types of technology can be investigated (Perrin \& Rueter, 1996). 
Within the larger FIPSE project, the faculty from across the disciplines taught 3,502 students throughout the academic year. Each technology-enhanced course taught was matched to an equivalent non-enhanced course. In some cases, the control and experimental courses were taught by the same instructor; however, some matched sets had different instructors. A pre-course and a post-course survey was administered to students in both the enhanced courses and the non-enhanced courses. Refer to Appendix A for the pre-course survey and Appendix B for the post-course survey. This survey asked about students' attitudes towards technology, general and coursespecific motivation, and satisfaction with the course. Portland State University's student information system provided information about student academic progress (e.g. adding or dropping courses, final grades, and GPA.)

The research project discussed here included only a subset of the courses that are being tested in the larger FIPSE project. The criteria for inclusion in this research was that the experimental and control courses were taught by the same instructor These criteria eliminated all but three courses that will be described below.

\section{Data Collection Procedure}

The data collection process began by accessing enrollment records for each of the courses on the specified data collection day. This was done to estimate the number of surveys needed for each course and establish the foundation for data entry and student tracking. Each course was attended by one of the primary investigators (PI) for the grant-based study as well as at least one research assistant. The research team members arrived at each course approximately fifteen minutes before the official start of class and began passing out questionnaires as students arrived. Once a large portion of the class was seated the PI in attendance introduced the project and explained that 
participation was voluntary, and confidential, and that we would be asking them to fill out another survey at the end of the quarter. The students were asked to complete the survey at that time, after the surveys were completed, the research team gathered all the surveys and exited. This process usually took 15 minutes of the class time. In some cases, the instructor was in the classroom; however, in some cases the instructor waited outside the classroom until all the surveys were returned. Once all the precourse data was collected it was determined that some of the courses had a low percentage of the students participate in the survey. As a team, we were unsure as to the reasons, so we returned to course with an under $70 \%$ return rated and tried to recruit students who has not previously taken the survey. Overall, this second attempt was unsuccessful in significantly increasing participation, some speculations as to why this was unsuccessful are presented in the results and discussion section of this thesis.

The post-course data collection took place during the last week of classes. One PI and at least one research assistant went to each of the classes on a selected day during the last week of class and followed the data collection protocol as described above. One addition to the protocol was that candy was passed out to those individuals that returned completed surveys, and those people also could enter their name into a drawing for four $\$ 25.00$ gift certificates to the University bookstore. It was decided that we would schedule a second data collection attempt on the day of the final exam if participation was below $70 \%$. Even though second attempts at data collection were not fruitful in the pre-course data collection, the research team believed that attendance would be high in all courses during the last week of finals, and for those students that were not in attendance would surely be at the final exam. Overall, this second attempt insignificantly raised the response rate. Participation rates for the courses in this thesis are in Table 1 and Table 2. 
Table 1

Fall Term Participation Rates

\begin{tabular}{l|cccccc}
\hline Course \& Level & $\begin{array}{c}\text { Pre-Course } \\
\text { Surcys } \\
\text { Returned }\end{array}$ & $\begin{array}{c}\text { Week 1 } \\
\text { Enrollment }\end{array}$ & $\begin{array}{c}\text { Pre-Course } \\
\text { Participation } \\
\text { Percentage }\end{array}$ & $\begin{array}{c}\text { Post- } \\
\text { Course } \\
\text { Surveys } \\
\text { Returned }\end{array}$ & $\begin{array}{c}\text { Week 10 } \\
\text { Enrollment }\end{array}$ & $\begin{array}{c}\text { Post-Course } \\
\text { Participation } \\
\text { Percentage }\end{array}$ \\
\hline \hline Psycliology/300 & 125 & 197 & 63.45 & 144 & 198 & 72.73 \\
Sociology/200 & 97 & 133 & 72.93 & 75 & 133 & 56.39 \\
Biology/300 & 144 & 120 & 95.00 & 76 & 106 & 71.70 \\
\hline
\end{tabular}

Table 2

\begin{tabular}{l|cccccc}
\hline \multicolumn{7}{c}{ Winter Term Participation Rates } \\
\hline Course \& Level & $\begin{array}{c}\text { Pre- } \\
\text { Course } \\
\text { Surveys } \\
\text { Returned }\end{array}$ & $\begin{array}{c}\text { Week 1 } \\
\text { Enrollment }\end{array}$ & $\begin{array}{c}\text { Pre-Course } \\
\text { Participation } \\
\text { Percentage }\end{array}$ & $\begin{array}{c}\text { Post- } \\
\text { Course } \\
\text { Surveys } \\
\text { Returned }\end{array}$ & $\begin{array}{c}\text { Week 10 } \\
\text { Enrollment }\end{array}$ & $\begin{array}{c}\text { Post-Course } \\
\text { Participation } \\
\text { Percentage }\end{array}$ \\
\hline Psychology/300 & 147 & 211 & 69.67 & 168 & 211 & 79.62 \\
Sociology/200 & 62 & 85 & 72.94 & 48 & 103 & 46.60 \\
Biology/300 & 104 & 116 & 89.66 & 72 & 110 & 65.45 \\
\hline
\end{tabular}

Variables in the Model

Refer to Table 3 and Table 4 for complete summary of variables in the model. The variables were selected based on an exploratory factor analysis of a subset of the larger study's variables. The three selected Attitude variables measured students' general attitude toward challenging course work, and graduate level education (e.g., I prefer classes that challenge me to those in which I can get an easy grade; I like classes where I have to work hard to master the material; I will probably do graduate work after I finish college). These questions are on page 1-C of Appendix A and are items 1, 6 , and 7 of the general section. 
Table 3

Pre-Course Variables in the Model

\begin{tabular}{l|l|l}
\hline \multicolumn{1}{c}{ Attitude } & \multicolumn{1}{c}{$\begin{array}{c}\text { Perceived Behavioral } \\
\text { Control-Time 1 }\end{array}$} \\
\hline $\begin{array}{l}\text { I prefer classes that challenge me to } \\
\text { those in which I can get an easy } \\
\text { grade. }\end{array}$ & $\begin{array}{l}\text { I feel that I will do well in this } \\
\text { class. }\end{array}$ & $\begin{array}{l}\text { I think I will enjoy studying for this } \\
\text { class. }\end{array}$ \\
\hline $\begin{array}{l}\text { I like classes where I have to work } \\
\text { hard to master the material. }\end{array}$ & $\begin{array}{l}\text { I fell confident that I will get a } \\
\text { good grade in this class. }\end{array}$ & $\begin{array}{l}\text { I plan to work hard on my homework } \\
\text { for this class. }\end{array}$ \\
\hline $\begin{array}{l}\text { I will probably do graduate work } \\
\text { after I finish college. }\end{array}$ & $\begin{array}{l}\text { I have a high standard for my } \\
\text { performance in this class. }\end{array}$ & I think I will enjoy this class. \\
\hline & & $\begin{array}{l}\text { I think I will enjoy doing outside } \\
\text { readings and projects for this class. }\end{array}$ \\
\hline
\end{tabular}

Table 4

Post-Course Variables in the Model

\begin{tabular}{|c|c|c|}
\hline $\begin{array}{c}\text { Perceived Behavioral } \\
\text { Control-Time } 2\end{array}$ & $\begin{array}{c}\text { Behavior } 1 \\
\text { Post-Course Self-Report }\end{array}$ & $\begin{array}{c}\text { Behavior } 2 \\
\text { Percent Correct on } \\
\text { Common Exam Questions }\end{array}$ \\
\hline I feel I did well in this class. & I enjoyed studying for this class. & \\
\hline $\begin{array}{l}\text { I feel confident that I got a good } \\
\text { grade in this class. }\end{array}$ & $\begin{array}{l}\text { I worked hard on my homework for } \\
\text { this class. }\end{array}$ & \\
\hline \multirow[t]{2}{*}{$\begin{array}{l}\text { I had a high standard for my } \\
\text { performance in this class. }\end{array}$} & I enjoyed this class. & \\
\hline & $\begin{array}{l}\text { I enjoyed doing outside readings } \\
\text { for this class. }\end{array}$ & \\
\hline
\end{tabular}

The three items selected to represent $\underline{P B C}$ measured a student's belief in their ability (e.g., I fell that I will do will in this class; I feel confident that I will get a good grade in this class; and I have a high standard for my performance in this class). These are items 1, 5, and 7 of the course specific questions on page 1-C of Appendix A.

The four items that measured Intention reflected a student's plan to achieve in the specific course (e.g., I think I will enjoy studying for this class; I plan to work hard at my homework for this class; I think I will enjoy this class; and I think I will enjoy doing outside readings and projects for this class). These variables were edited for tense and comprise the Behavior 1 measure. These are items $3,4,8$, and 9 of the course specific section on page 1-C of Appendix A. 
The Behavior 2 measure is the percentage correct on common exam questions. The are identical questions given to students in both the control and experimental matched sets

\section{$\underline{\text { Participants }}$}

483 volunteer subjects were students currently enrolled in courses at Portland State University. There were six courses in which participant recruitment took place; two sections of each of the following: Human Development, Introduction to Sociology, and Introduction to Genetics. The aforementioned courses were 200 level or 300 level and had between 85 and 211 students enrolled each quarter. Refer to Table 1 and 2 for enrollment figures.

These courses are part of a grant-based study investigating the effects of technology and assessment on learning in large classrooms. The faculty participating in this project have been trained in the use of a variety of technological tools (e.g., multimedia presentation, Internet access, e-mail) as well as assessment in the classroom. Each instructor taught one course with technology and assessment and the same course without technology and assessment.

\section{Materials}

The materials consisted of two packets distributed to each student. The first packet (pre-course measures) was distributed during the first week of class and was completed during class time. The second packet (post-course measures) was distributed the last week before finals and was completed during class time.

The introductory page of the pre-course measures requested the last six digits of the subjects social security number for matching purposes. Page two was the 
consent form that explains completion of the survey implies consent. Page 1-A requested demographic and other information such as gender, age, credit hours, experience with computers, and employment status. Page 1-B and 1-C were precourse measures investigating attitudes towards computers and motivation, respectively. Page 1-D asked why participants were enrolled in the course as well as their preferences regarding the use of technology within the classroom

All measures were locally developed and tested for reliability and validity during the 1995-96 academic year. The attitude survey began as a 97-item compilation of six computer anxiety scales (Stevens, 1982; Reece \& Gable, 1982; Gressard \& Lloyd, 1986; Griswoold, 1983; Maurer \& Simonsen, 1983; and Dukes, Discenza, \& Cougar, 1989). This compilation included behavioral, cognitive and affective items, as well as computer liking, computer confidence, computer anxiety, and computer interest. After editing for irrelevant and duplicate items, 56 items remained. Of these items, half were negatively worded and half were positively worded. All items were based on a 6-point Likert scale ranging from 1 (Strongly Disagree) to 6 (Strongly Agree) and were administered to 194 students in two courses, one day class and one night class. Factor analysis and item analysis were used to eliminate items. The questionnaire had three factors with a total of 18 items. The usefulness factor consisted of items $1,2,8,10$, 12, 18, from page I-B of Appendix A and had a reliability of 8048 . The liking/interest factor included item numbers $4,6,14$, and 16, and had a reliability of .7129. The final factor, comfortableness/confidence, consisted of eight items: $3,5,7,9,11,13,15$, and 17 , and had a reliability rating of 8753 . All the aforementioned items can be found on page I-B of Appendix A.

The motivation survey originated with 42 items from Baker and Siryk's (1984) Academic and Motivation Scale edited for population appropriateness, and an 
additional eight items were added based on Biddle and Brooke's (1992) Motivational Orientation Support Scale. Of the 50 items, 18 were eliminated due to irrelevance or duplication. The resulting 32 items were split into two scales; general academic motivation (14 items) and specific course motivation (18 items). All items were scored on a 6-point Likert scale ranging from 1 (Strongly Disagree) to 6 (Strongly Agree) This pilot survey was administered to students $(\mathrm{N}=258)$ from three courses: 132 from introductory biology; 46 from geology; and 80 from developmental psychology.

Factor analysis and item analysis of the general motivation scale produced a 7item scale accounting for $40.25 \%$ of the variance, with a reliability of 7335 . Factor and item analysis of the course specific motivation scale resulted in a 12-item scale accounting for $48.7 \%$ of the variance and a reliability rating of 8970 . To complete the factor analysis of the scales, all 19 items were analyzed simultaneously. The results proved that the two factors accounted for $45 \%$ of the variance and were discrete factors

For the post-course measurement, the last six digits of the subjects' social security number were collected for matching purposes. Additionally, the attitudes towards computers and motivation measures were completed as well as the preferences regarding the use of technology in the classroom. Items were edited for tense when needed. Included with the post-course packet was a learning style inventory and a 34item course evaluation

\section{Design}

This is secondary data analysis from a larger grant-based study investigating the effects of educational technology using a matched-pairs pre-test post-test design. A subset of the data was used for this study; three large classes, 85 to 211 students per 


\section{Educational Technology Page 33}

course, from three disciplines. The courses selected represented the psychology, sociology and biology departments. Additionally, the course sections were 200 or 300 level.

The selection of these classes to participate in the analysis were based on the fact that each faculty member taught two courses; the control course first and then the experimental course 


\section{Results}

There were 483 respondents that participated in both Time 1 and Time 2 data collections: 235 respondents were in the control condition and 248 were in the experimental condition. Thirty-six percent were male and $62 \%$ were female, $2 \%$ of the subjects did not indicate their gender. Demographics of the participants follow: $14 \%$ were freshmen, $14 \%$ were sophomores, $37 \%$ were juniors, $23 \%$ were seniors, and $11 \%$ were post-baccalaureates or graduate students taking an average of 13 undergraduate credits with a range of 4 to 24 quarter credits. Sixty-eight percent were employed working an average of 12 hours per week, ranging from 2 to 90 hours per week. Of all respondents, $69 \%$ indicated owning a personal computer, and $29 \%$ otherwise having easy access to a computer. Fifty-seven percent of the respondents indicated familiarity with the DOS operating system while $64 \%$ indicated understanding the Macintosh operating system, and $90 \%$ had experience with Microsoft Windows based systems. Students indicated word processing as the primary reason for using computer, $97 \%$, while $45 \%$ used database programs; $46 \%$ had experience with graphics/presentation; $15 \%$ with programming; $22 \%$ with statistical packages; $57 \%$ with spreadsheets; $72 \%$ used e-mail; $66 \%$ accessed the Internet/WWW; $0.1 \%$ used simulations; and $71 \%$ had used a computer to play games. Other participant information includes: $48 \%$ had an e-mail account that could be accessed from their home; $33 \%$ could access the WWW from home; $5 \%$ had been diagnosed with a learning disability; and $24 \%$ had completed Freshman Inquiry or Transfer Inquiry (a University program that is part of the general education curriculum)

\section{Testing the Measurement Model}


The measurement model was examined first. The measurement model can be seen in Figure 8. It is illustrated by the relationship between the measured variables (boxes) and the latent variables (circles). This model is also representative of Behavior 2 , however, there is only one measured variable for Behavior 2 .

Figure 8

Measurement Model

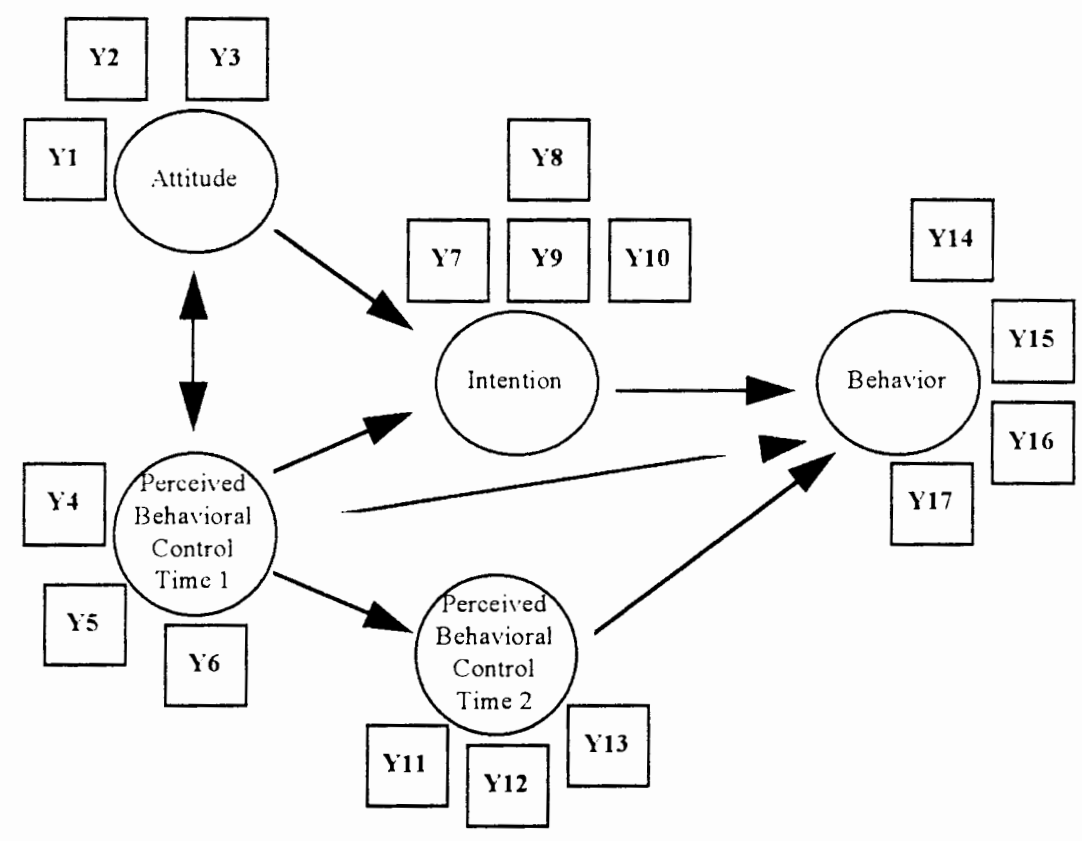

Originally, the survey items that fit the model were read and categorized into each factor by two raters. At that time the items appeared to fit into the categories of Attitude, Perceived Behavioral Control (PBC), or Intention in a clear and concise manner; however, a confirmatory factor analysis did not confirm the factors as originally hypothesized

Next, an exploratory factor analysis was conducted on the Time 1 data to determine if an alternate structure existed. Three factors that could be interpreted as 
Attitude, PBC, and Intention were found. However, when the variables were examined not all appeared to be related to a single factor. Two variables were dropped from Attitude because they did not load solely on the Attitude factor. The two dropped variables were "this class" variables, meaning that the response was to be indicative of their attitudes only for that class in which they were completing the survey and not their courses as a whole. These variables were "Doing well in this class is important to me" and "I am not very interested in this class." Also, one variable (I plan to keep up with my daily classwork) was dropped from the Intention due to loading on more than one factor.

A second factor analysis was run on the remaining 10 Time 1 variables. All variables loaded on one of the three factors; Attitude, PBC-Time 1, or Intention. This factor analysis accounted for $72 \%$ of the variance in the data. Table 5 presents the factor loadings. 
Table 5

Exploratory Factor Analysis

Factor Loadings for Behavior 1-Self Report Measures

\begin{tabular}{|c|c|c|c|c|c|}
\hline & Attitude & PBC-T1 & Intention & PBC-T2 & Behavior \\
\hline \multicolumn{6}{|l|}{ Time 1 Variables } \\
\hline Y1: Prefer classes that challenge me & .661 & .015 & .077 & & \\
\hline I2: Like classes where I have to work hard & .772 & .089 & .061 & & \\
\hline 13: Probably do graduate work after college & .323 & .235 & .058 & & \\
\hline Y 4: Confident that will get a good grade & .021 & .841 & .031 & & \\
\hline I5: Feel I will do well in this class & .000 & .909 & .042 & & \\
\hline Y6: Have high standard for performance & .106 & .577 & .186 & & \\
\hline Y7: Will enjoy studying for this class & .021 & .047 & .795 & & \\
\hline Y8: Enjoy doing outside readings and projects & .082 & .120 & .763 & & \\
\hline Y9: Plan to work hard at homework & .053 & .347 & .468 & & \\
\hline Y10: Think I will enjoy this class & .112 & .172 & .830 & & \\
\hline \multicolumn{6}{|l|}{ Time 2 Variables } \\
\hline Y11: Feel confident that got a good grade & & & & .923 & .010 \\
\hline Y'12: Feel I did well in this class & & & & .903 & .011 \\
\hline Y13: Had a high standard for my performance & & & & .367 & .408 \\
\hline 14: Enjoyed studying for this class & & & & .001 & .908 \\
\hline Y15: Enjoyed outside readings & & & & .132 & .850 \\
\hline 16: Worked hard at my hometiork & & & & .151 & .555 \\
\hline 117: Fnjoyed this class & & & & .042 & .739 \\
\hline
\end{tabular}

As showed in Table 5, the Attitude factor addressed general beliefs about success in college, such as a student's attitudes towards challenging coursework and the continuation of their education. PBC-Time 1 reflected a general feeling of control over performance in the course, such as confidence in their ability to perform and personal performance standards set for themselves in that particular class. The Intention variable reflected specific plans to complete required coursework in order to succeed, such as planning to work hard at homework and enjoying outside projects and readings for that class

To replicate the Time 1 pattern found in the aforementioned factor analysis an exploratory factor analysis was conducted on the Time 2 variables. Table 5 also presents the factor loadings for this analysis. As seen in Table 5, the factor pattern 
remained consistent with the Time 1 variables, and clearly indicated two distinct factors. PBC-Time 2 addressed a student's perception of success in that course and their personal level of achievement desired in that class. The Behavior factor determined if student's followed through on their intentions for success in the course. The factor analysis on the Time 2 variables accounted for $73.5 \%$ of the variance in the data

The measurement model described above is reflective of the Behavior 1-Self Report Measures. While the measurement model for Behavior 2-Common Exam Questions was not specifically tested. The only difference between Behavior 1 and Behavior 2 is the reliance on a single indicator for Behavior 2. All other measurement variables remain constant between the two models.

\section{Testing the Structural Model}

To test the model, in Figure 9 and the corresponding hypotheses, covariance structure modeling by groups was performed on the data using LISREL. The groups were labeled control for the non-enhanced courses and experimental for the enhanced courses. For the analysis, two models were estimated. The first constrained all structural paths in the experimental group to equal the control group path coefficients In the second analysis, $\Psi_{2,1}, \mathrm{~B} 1$, and B2 were constrained to be equal for both groups All other paths were allowed to vary. For the first step, the maximum likelihood estimates of the path coefficients were estimated using the control group subjects. These estimates were then used to conduct a covariance structure modeling by groups in which all the structural paths were constrained to be equal for the two conditions. For the second step, a new covariance structural modeling by groups was run with only the specified paths $\Psi_{2,1}, \mathrm{~B} 1$, and B2 being constrained to be equal for the two 
conditions. The analysis in which all the paths were constrained to be equal is the fully constrained model. The analysis with only the selected paths constrained is the partially constrained model. These two models were compared using a chi-square difference test. This entire process was repeated for Behavior 2, the common exam questions. Refer to Table 8 for goodness-of-fit information.

$\Psi_{2,1}, \mathrm{~B} 1$, and B2 were the paths selected to be constrained to be equal because they are reflective of the paths within Time 1. It was hypothesized that the difference between the control and experimental conditions would occur between Time 1 and Time 2 due to the use of technology and assessment in the classroom.

Figure 9

Structural Model

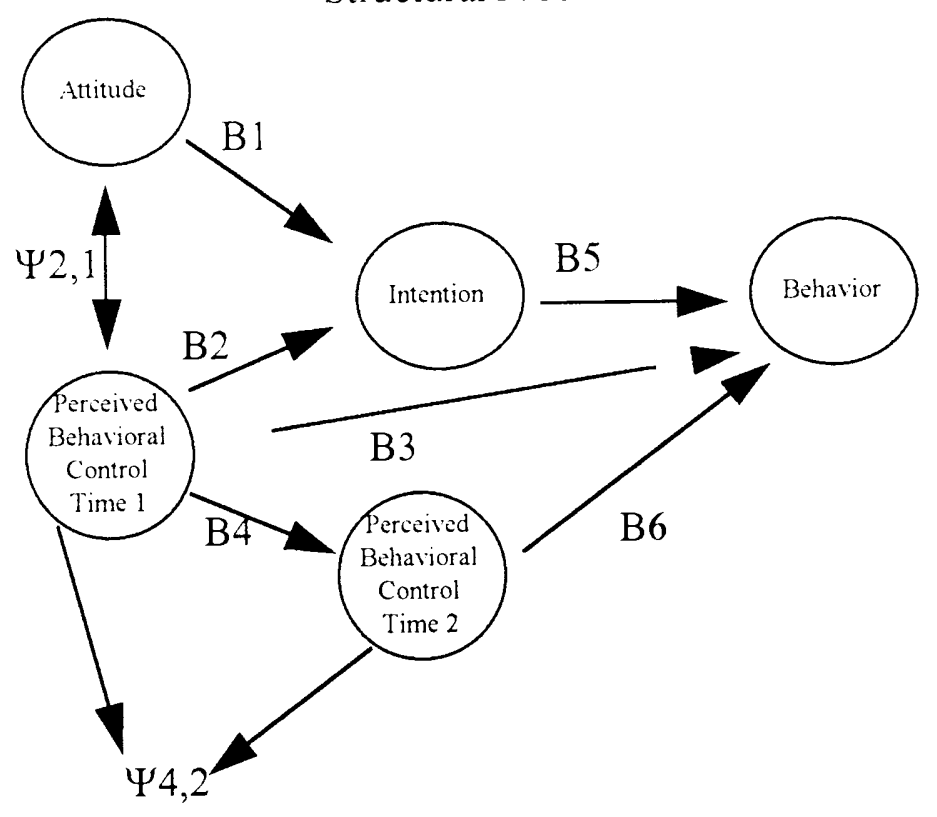


The measurement model for the control and experimental groups are presented in Table 6 and Table 7. This is the common metric solution from the covariance structure modeling by groups. As expected, these factor loadings closely resemble the factor loadings from the exploratory factor analysis detailed in Table 5 .

Table 6

Measurement Model Factor Loading

for Behavior 1 (Self Report Measures)

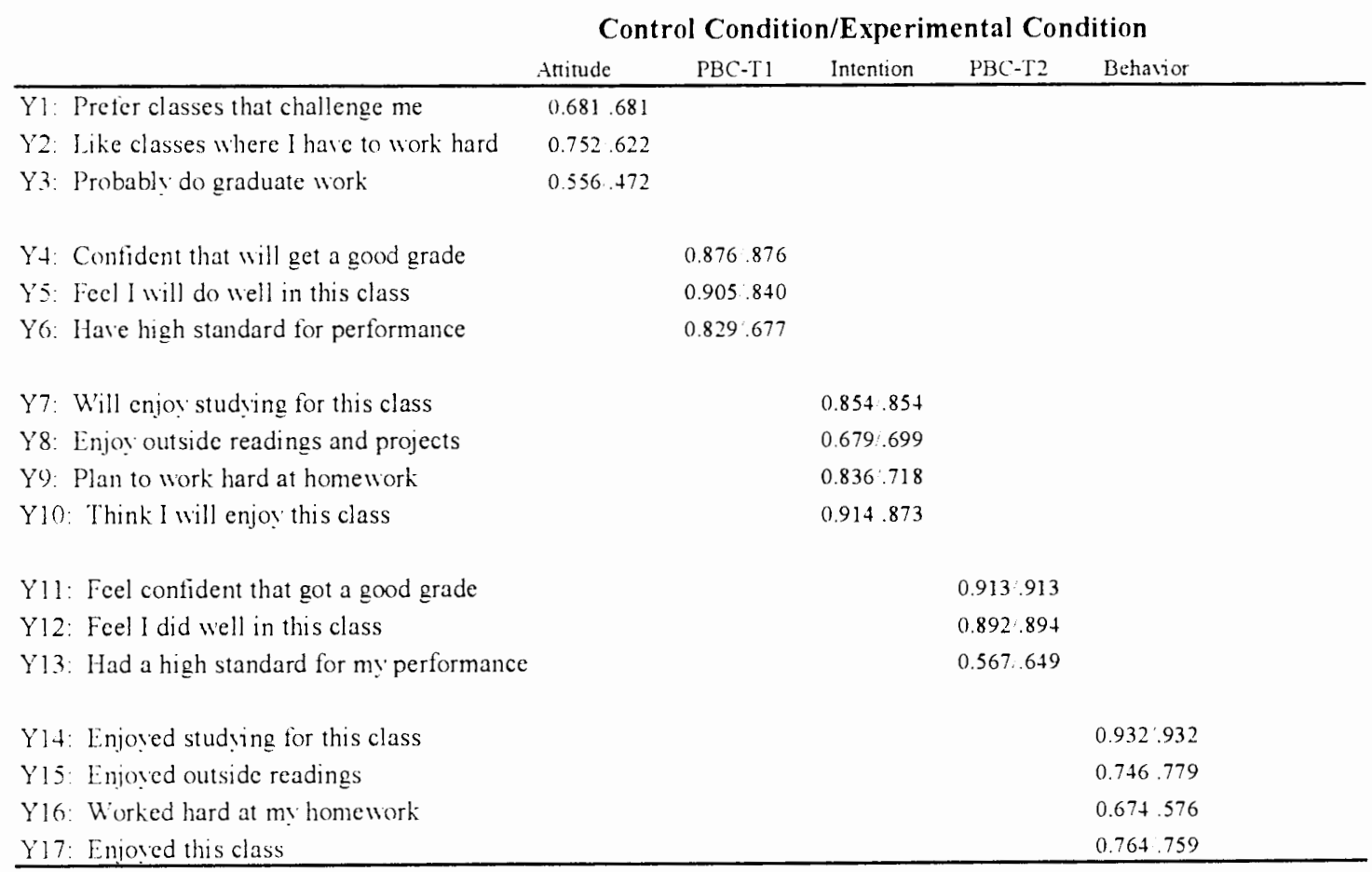


Table 7

Measurment Model Factor Loadings

for Behavior 2 (Common Exam Questions)

Control Condition/Experimental Condition

\begin{tabular}{|c|c|c|c|c|c|}
\hline & Allitude & $\mathrm{PBC}-\mathrm{T} 1$ & Intention & PBC-T2 & Behavior \\
\hline Y1: Prefer classes that challenge me & .677 .677 & & & & \\
\hline Y2: Like classes where I have to work hard & .745 .628 & & & & \\
\hline Y3: Probably do graduate work & $541: 482$ & & & & \\
\hline Y4: Confident that will get a good grade & & .879 .879 & & & \\
\hline Y5: Feel I will do well in this class & & .903 .845 & & & \\
\hline Y6: Have high standard for performance & & .823 .681 & & & \\
\hline Y7: Will enjoy studying for this class & & & .855 .855 & & \\
\hline Y8: Enjoy outside readings and projects & & & .673 .710 & & \\
\hline Y9: Plan to work hard at homework & & & .837 .716 & & \\
\hline Y10: Think I will enjoy this class & & & $.907: 880$ & & \\
\hline Y11: Feel confident that got a good grade & & & & .913 .913 & \\
\hline Y12: Feel I did well in this class & & & & .892 .911 & \\
\hline Y13: Had a high standard for my performance & & & & .555 .610 & \\
\hline Y14: Percentage Correct & & & & & 1.01 .0 \\
\hline
\end{tabular}

Fifty-six percent of the variance was explained in Behavior 1-Self Report

Measures, within the control condition. That increased to $59.1 \%$ within the experimental condition. For Behavior 2-Common Exam Questions, $12.9 \%$ of the variance was explained in the control condition, increasing to $19.2 \%$ within the experimental condition. In both Behavior measures, the amount of variance explained was higher in the experimental condition. The root mean square residuals were at acceptable levels $(<.10)$ and the goodness-of-fit indices were above 80 . Refer to Table 8 for complete goodness-of-fit information on Behavior 1 and Behavior 2. 
Table 8

Goodness-of-Fit Table

\begin{tabular}{|c|c|c|c|}
\hline & RMSR & GFI & $\begin{array}{c}\text { Variance } \\
\text { Accounted for }\end{array}$ \\
\hline \multicolumn{4}{|l|}{ Behavior 1-Self Report Measures } \\
\hline \multicolumn{4}{|l|}{ Fully Constrained Model } \\
\hline Control & 0.073 & 0.866 & $56.30 \%$ \\
\hline Experimental & 0.087 & 0.858 & $60.80 \%$ \\
\hline \multicolumn{4}{|l|}{ Partially Constrained Model } \\
\hline Control & 0.073 & 0.866 & $56.30 \%$ \\
\hline Experimental & 0.083 & 0.861 & $59.10 \%$ \\
\hline \multicolumn{4}{|c|}{ Behavior 2-Common Exam Questions } \\
\hline \multicolumn{4}{|c|}{ Fully Constrained Model } \\
\hline Control & 0.062 & 0.903 & $12.90 \%$ \\
\hline Experimental & 0.094 & 0.874 & $12.80 \%$ \\
\hline \multicolumn{4}{|l|}{ Partially Constrained Model } \\
\hline Control & 0.062 & 0.903 & $12.90 \%$ \\
\hline Experimental & 0.086 & 0.880 & $19.20 \%$ \\
\hline
\end{tabular}

\section{Model Comparison \& Hypothesis Results}

For Behavior 1, the fully constrained model resulted in a $\mathrm{X}_{(236)}=632.19$ and the partially constrained model resulted in a $X^{2}{ }_{(228)}=624.13$. The chi-square difference test failed to reject the null hypothesis that the models fit the data equally well $\left(\mathrm{X}^{2}{ }_{(8)}=8.06\right)$. For Behavior 2 , the fully constrained model resulted in a $\mathrm{X}_{(154)}=$ 395.39 and the partially constrained model resulted in a $X_{(146)}^{2}=387.26$. The chisquare difference test again failed to reject the null hypothesis that the models fit the data equally well $\left(\mathrm{X}^{2}{ }_{(8)}=8.13\right)$.

Regarding the hypotheses, hypothesis \#1 proposed that the path from $\underline{\mathrm{PBC}-}$ Time 1 to Behavior would be stronger in the enhanced courses than the non-enhanced courses. However, the sign of this path was negative for Behavior 1 with the beta for 
the control and experimental conditions being -.729 , and -.536 , respectively. For $\underline{B}$ havior 2 , the path coefficients were in the predicted direction and order. The $\underline{\mathrm{PBC}}-$ Time 1 to Behavior path coefficient for the control condition was .066 , and 102 for the experimental condition. These paths were non-significant. Refer to Figure 10 for the Behavior 1 path coefficients, and Figure 11 for the Behavior 2 path coefficients.

Figure 10

Control \& Experimental Condition Path Coefficients for

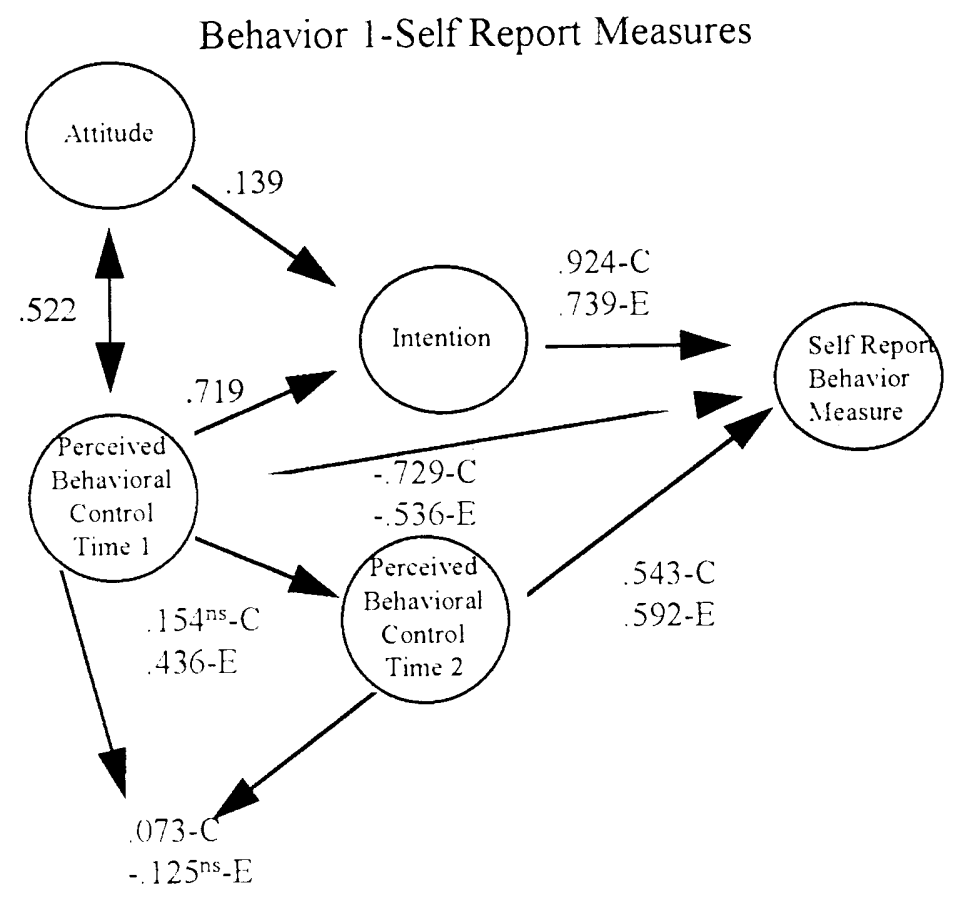


Figure 11

Control and Experimental Path Coefficient for

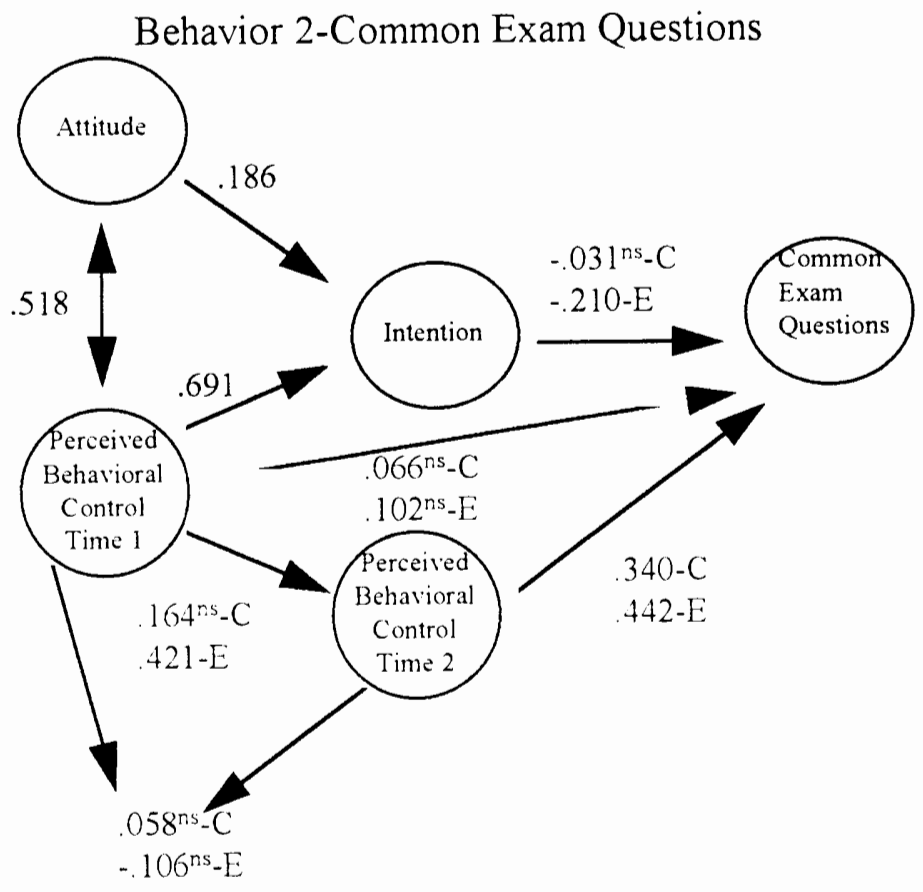

The second hypothesis addressed the path from Intention to Behavior. The path coefficient for Behavior 1 control and experimental condition was .924 and .739 respectively. The stronger path was with the control condition, contrary to this hypothesis. For Behavior 2 , the control condition path coefficient was -.031, and -.210 for the experimental condition. This negative relationship between Intention and Behavior was unexpected and will be addressed in the discussion section.

The third hypothesis addressed the relationship between the path from $\underline{\mathrm{PBC}-}$ Time 1 and PBC-Time 2 with the Behavior measures. It was hypothesized that the path from Time 2 would be stronger than the path from Time 1 in the enhanced courses compared to the non-enhanced courses. For Behavior 1, the PBC-Time 1 control condition path coefficient was -.729 and the $\underline{\text { PBC-Time } 2}$ path to Behavior was .543 
In the experimental condition, the Time 1 path was -.536 and the Time 2 path was 592.

For Behavior 2, the path coefficient from PBC-Time 1 to Behavior was 066 and 340 for the path from PBC-Time 2 to Behavior within the control condition Within the experimental condition, the PBC-Time 1 to Behavior path was .102 and the PBC-Time 2 to Behavior path coefficient was .442. In both the control and experimental conditions, the path from $\underline{\mathrm{PBC}-\mathrm{Time} 1}$ to Behavior was non-significant

To determine if the change in PBC over time was the same for the control and experimental conditions, a repeated measures ANOVA was conducted. Results indicated that there was no difference in PBC over time between the control and experimental conditions. The mean for PBC-Time 1 was 15.33 for the control condition and 15.46 for the experimental. The mean for PBC-Time 2 was 14.13 for the control condition and 14.49 for the experimental condition. While the mean decreased over time, there was no statistical difference. These results, while not statistically significant, suggest a similar change over time as found by Ajzen \& Madden (1986) when they found that students decreased their perception of control over time when students were asked to predict their final grade in a course 
Educational Technology Page 46

Discussion

\section{Behavior 1-Self Report Measures}

When testing the self report measures, the paths from Attitude and PBC-Time 1 to Intention, as well as the correlation between Attitude and PBC-Time 1 were constrained to be equal in both the control and experimental conditions. These paths were forced to be equal on the assumption that students, in both conditions, would have the same Time 1 relationship among the factors. As Figure 10 shows, the path from PBC-Time 1 to Intention was stronger than the path from Attitude to Intention. This indicated that perception of control during the beginning of a course had a stronger influence on students' intentions to perform well in a course than their general attitude towards challenging coursework

While the path from PBC-Time 1 to the self-report measures was significant for both conditions the existence of a negative relationship between these factors suggest that some students who start with a high level of control over their performance in a course do not report doing well in the course based on self report data, such as enjoying the class or working hard at homework and readings for the course. This negative relationship was not at all expected, nor was this possibility discussed in the literature. Ajzen \& Madden (1986) did state that when testing their version of this model that a strong effect from PBC to the Behavior measure, "is expected under two conditions. First, the behavior being predicted must not be under complete volitional control" and "Second, perceptions of behavioral control must reflect actual control in the situation with some degree of accuracy" (p. 460). It could be stated that when testing this model, the use of self-report outcome measures make the behavior under volitional control, meaning that a student could decide at will to have a high sense of confidence or a high standard for their performance, or not. However, the use of self- 
report outcomes should not make this path negative, it should just decrease it's strength. The second requirement stated by Ajzen indicates that there needs to be a correlation between perception of control and actual control. With the data available, it is impossible to determine if this was the case. However, it is assumed that if a student is confident and has a high performance standard, that student would do the required coursework in order to succeed. On the other hand, a student may have a high sense of control, but merely be in a classroom where their skills are not at the level expected by the instructor. It was expected that this path would be positive, but weaker, than the path from PBC-Time 2 to the self report behavior measures. While this negative relationship exists between perception of control (Time 1) and self-report behavior, it is important to note that the path coefficients indicates that increased feedback and the use of technology assists in lessening this negative effect. Meaning that, for those students who have difficulty adjusting their perception of personal control in the classroom can benefit from course embedded assessment and educational technology.

The path from PBC-Time 1 to PBC-Time 2 was significant only for the experimental condition. This significant path found in the experimental condition indicated that a high level of control at Time 1 was associated with a high level of control at Time 2. Suggesting that the use of assessment and technology in the classroom assists in maintaining a strong sense of personal control over success in the classroom, for those students who come into the classroom with it already. On the other hand, in the control condition, there was no relationship between their perception of control in the course at the first week of the course and the last week. In this condition, some students increased their perception of control while others decreased, with no consistent pattern of change. 
The path from PBC-Time 2 to the self report behavior measures was significant for both conditions. This positive and significant path indicated that students who indicated a high level of control over their performance in the classroom also indicated more positive student outcomes. Meaning that students who had confidence and high standards for their classroom performance also indicated enjoying the class and working hard to complete the required coursework for a good grade. Also, the experimental condition path coefficient indicated that the link between these two factors was stronger for the experimental condition than for the control condition.

The path from Intention to the self report behavior measures was significant for both conditions. This path suggested that students who planned to succeed in the course also reported good student outcomes, such as enjoying studying and working hard at homework. This pattern was reflected in both conditions suggesting that a plan for success, or the intention to succeed, was a strong indicator. The high path coefficients seen in this path are consistent with Ajzen \& Madden's (1986) explanation of the model. They wrote, "the immediate antecedent of any behavior is the intention to perform the behavior in question. The stronger a person's intention, the more the person is expected to try, and hence the greater the likelihood that the behavior will actually be performed" (p. 454, italics in original). In this case, Intention and Behavior contain the same survey item, they are just collected at two time points. Therefore, there should be a strong path from Intention to Behavior.

\section{Behavior 2-Common Exam Questions}

As with self report behavior measure, the path coefficients between the Time 1 factors were constrained to be equal based on the assumption that students, in both conditions, would have the same relationship between these variables. All these paths 
were significant and positive in their relationships, and reflected the same pattern of relationship as was seen in the self report behavior measure model.

The path from perception of control (Time 1) to percentage correct on the common exam questions was non-significant for both conditions. This indicated that when using an objective behavior measure, a student's confidence and performance standard at Time 1, is not an indicator of success on mid-term and final exams. This makes intuitive sense, because early in the term a student does not have an adequate determination of the difficulty of the course, or the requirements of the faculty, thus making it difficult to accurately predict success using an objective measure.

The change in perception of control over time, reflect the same pattern as in the previous model. The path from Time 1 to Time 2 is significant only for the experimental condition. This indicates that within the experimental condition, a high sense of confidence and performance standard at the beginning of the term is maintained throughout the course. However, in the control condition, the pattern of change is not consistent; some students increase their control while other decrease their perception of control.

The path from PBC-Time 2 to the percentage correct behavior measure was significant for both conditions. This indicates that a high sense of confidence and a high performance standard at Time 2 was reflected in higher exam scores. This positive and significant path indicates that students who believe they will succeed in the class and have a high performance standard do what is needed in order to receive high marks on their exams. Also, the path coefficient was stronger in the experimental condition than the control condition indicating that a higher sense of confidence and standards was reflected in their exam scores. 
The path from Intention to the percentage correct behavior measure was significant only for the experimental condition. While this path was significant it was also negative for both the control and experimental conditions. This negative relationship between a students' plan to work hard at homework and enjoy the class and performance on mid-terms and final exams was unexpected. It indicates that a high sense of enjoying the class and required coursework is not consistent with a high percentage correct on the exams. Therefore, even though a student may plan on working hard at homework and outside readings, and generally enjoying the class, this plan doesn't reflect itself in an objective measure assigned by a faculty member. This finding replicates Ajzen \& Madden's (1986) finding of a non-significant correlation between Intention and Behavior when using an objective measure of Intention, as was used in this model.

\section{General Discussion}

It was expected that students would begin a course with an initial sense of personal control, and that level of control would be adjusted throughout the term based on feedback from assessments, class discussions, quizzes, and the technology interactions, and that higher sense of behavioral control would be associated with more positive behavior outcomes, such as enjoying the readings and the class. As discussed above, several paths within the model proved this expectation to be incorrect. The most unexpected path was from perception of control (Time 1) and the self report behavior measures. To understand this path, it was speculated that some students do not adjust their perception of control based on feedback, thus leading to a negative outcome. In the condition without course embedded assessment and technology this path was stronger, indicating that assessment and technology lessen this negative 
relationship. On the other hand, some students did adjust their personal control based on feedback leading to positive student outcomes such as reporting enjoying the course and working hard at homework and required readings

For students in the experimental condition, the relationship between PBC-Time 1 and Time 2 was consistent; however, this was not seen within the control condition Because the paths were stronger in the experimental condition, it could be considered that the use of course embedded assessment and educational technology assisted students in adjusting and maintaining their level of control through feedback and interactions.

As described in the introduction, Ajzen \& Madden (1986) indicated that the inclusion of a direct path from PBC to Behavior reflected a measure of actual control while the mediated path represents the perception of control. This model differs from Ajzen \& Madden's model in that PBC-Time 2 was added to the model. Therefore, the path from PBC-Time 1 to PBC-Time 2 to Behavior would be reflective of actual control while the path from PBC-Time 1 to Behavior reflected perception of control. If this distinction could be tested more thoroughly it would indicate that in this case, the negative path from PBC-Time 1 to Behavior was the perception of control and the actual control a student had was represented by the path going from PBC-Time 1 through PBC-Time 2 to Behavior, meaning that perception of control and actual control had very different relationships with the Behavior measure

The fact that the path from PBC-Time 1 to PBC-Time 2 to Behavior was positive and significant for the experimental condition indicated that the use of technology and classroom assessments increased student confidence resulting in more positive student outcomes. It is speculated that classroom assessment plays a larger role than the technology-based presentations considering the survey items that make up 
PBC. One purpose of classroom assessment is to provide feedback to students, this feedback allows faculty to make course corrections as needed as well as provides students with guidelines to ensure they are learning and integrating the course material as required by the instructor. The items within PBC refer to confidence, a feeling of doing well, and performance standards; all of which are directly impacted by feedback. Additionally, classroom assessments are much more active from a student perspective than technology-based presentations. While the data set used here cannot specifically test these speculations, future research could address these issues

One other important note is that the addition of PBC-Time 2 to the Theory of Planned Behavior strengthened the model, and supported Terry et. al's (1993) statement that additional variables should be considered in the Theory of Reasoned Action, which is a simpler version of the Theory of Planned Behavior. The addition of PBC-Time 2 to this model created a more interesting and complex dynamic with the Behavior measure and as Ajzen \& Madden (1986) indicated is indicative of actual control over a behavior.

This research project was a beginning step in understanding the role of assessment and technology in higher education. While some results found in this project were unexpected it was normally the case that students who experienced course-embedded assessment and technology-based presentations had stronger path coefficients than those students without these enhancements. Therefore, the implementation of course-embedded assessment and the increased use of technology in the classroom may provide students the necessary avenues needed for success in higher education.

Limitations of the Study 
When conducting applied research there are many difficulties in achieving a valid and reliable study, and research into the use of educational technology is not immune from these threats (Clark, 1985). One major issue within this study was the lack of control over student attendance. For example, 307 pre- or post-course surveys were not included in the final data set because students did not complete both a preand post-course survey. While the number of matched surveys was sufficient for this thesis, it was disappointing to lose so many surveys. During the course of the research project, several strategies were attempted to increase student participation, ranging from incentives to collecting data on high attendance days. Another issue that arose during this study regarding levels of control was the control over faculty following the protocol to allow for the research team to compare the control courses with the experimental courses. The matched set was originally designed to have Professor 1 teach his experimental course concurrently with another biology course being taught by Professor 2. It was originally agreed that Professor 1 would teach particular sections of Professor 2's course and those sections would be compared. However, Professor 2 altered the teaching schedule without informing Professor 1 nor the research team. This alteration resulted in Professor 1 only teaching in Professor 2's course for approximately one hour. Therefore, this set could not be included in this thesis since the criteria for inclusion was that the control and experimental sections had to be taught by the same professor.

Another limitation of this study is that it is a secondary data analysis, thus relying on survey items not specifically designed for this research project. The ideal situation would have been to design questions to specifically address the constructs within the model here; however, that delay may have sacrificed the availability of such a large sample size. 


\section{Future Research}

Further research needs to investigate each matched set of courses individually. Also, it is within the research agenda of this author to incorporate more matched sets into the data set in hopes that this increase in subjects will increase the statistical power to detect significant differences between the control and experimental conditions. Also, future research needs to identify methods to increase the number of students who complete both the Time 1 and Time 2 survey. It is also a goal to understand the relationship between the variables more clearly, especially the path between PBC-Time 1 and Behavior.

Other possibilities include the isolation of the effects of technology from assessment to determine if either one of these factors contributes to student outcomes more than the other. One possible method for achieving this is to measure the levels of assessment and technology usage in each classroom. This measurement would allow for an in-depth look into how each one of these components are being used, as well as the respective levels of success in increasing student outcome measures 


\section{References}

Anderson, J. A., \& Cichocki, R. R. (1992, Feb.) Media Equipped Classrooms: Giving Attention to the Teaching Station. Paper presented at the annual convention of the Association for Educational Communications and Technology, Washington, DC

Ajzen, I, Timko, C., \& White, J. B. (1982). Self-monitoring and the attitudebehavior relation. Journal of Personality and Social Psychology, 42(3), 426-435.

Ajzen, I., \& Madden, T. J. (1986). Prediction of goal-directed behavior: Attitudes, intentions, and perceived behavioral control. Journal of Experimental Social Psychology, 22, 453-474

Ajzen, I., \& Driver, B. L. (1992). Application of the theory of planned behavior to leisure choice. Journal of Leisure Research, 24(3), 207-224.

Angelo, T. A., \& Cross, K. P. (1993). Classroom Assessment Techniques: A Handbook for College Teachers. Second Edition. San Francisco: Jossey-Bass

Astin, A. W. (1993). Assessment for Excellence. The Philosophy and Practice of Assessment and Evaluation in Higher Education. Phoenix, AZ: Oryx Press.

Baker, R. W., \& Siryk, B. (1984). Measuring academic motivations of matriculating college freshmen. Journal of College Student Personnel, September, 459464.

Biddle, S., \& Brooks, R. (1992). Intrinsic versus extrinsic motivational orientation in physical education and sport. British Journal of Educational Psychology, $\underline{62}, 247-256$

Clark, R. E. (1985). Evidence for confounding in computer-based instruction studies: Analyzing the meta-analyses. Educational Communication and Technology Journal, 33 (4), 249-262 
Dukes, R. L., Discenza, R., \& Cougar, J. D. (1989). Convergent validity of four computer anxiety scales. Educational and Psychological Measurement, 49(1), 1004-1021

Farmer, D. W. (1988). Enhancing Student Learning: Emphasizing Essential Competencies in Academic Programs. Wilkes-Barre, PA: King's College Press.

Granrose, C. S. (1984). A Fishbein-Ajzen model of intention to work following childbirth. Journal of Vocational Behavior, 25 , 359-372.

Green, K. C. (1995). Technology use jumps on college campuses. The Campus Computing Project

Gressard, C. P., \& Lloyd, B. H. (1986). Validation studies of a new computer attitude scale. Association for Education Data Systems Journal, 18(4), 295-301

Griswold, P. A. (1983). Some determinants of computer awareness among education majors. Association for Education Data Systems Journal, 16(2), 92-103.

Klobas, J. E. (1995). Beyond information quality: Fitness for purpose and electronic information resource use. Journal of Information Science, 21(2), 95-114.

Kiwala, K. (1993). A Model to Predict Recycling Behaviors: Reusing Ajzen's Model One More Time. Unpublished thesis. Portland State University, Portland, OR. Kozma, R. B., \& Johnston, J. (1991). The technological revolution comes to the classroom. Change, Jan/Feb, 10-23.

Kulik, J., Kulik, C, \& Cohen, P. (1980). Effectiveness of computer-based college teaching: A meta-analysis of findings. Review of Educational Research, $\underline{50}$, $525-544$

Lamb, A. C. (1992). Multimedia and the teaching-learning process in higher Education. In M. J. Albright and D. L. Graf(Eds.), Teaching in the Information Age: 
The role of Educational Technology. New Directions for Teaching and Learning, $\underline{51}$, San Francisco: Jossey-Bass.

Manstead, A. S., Proffitt, C., \& Smart, J. L. (1983). Predicting and understanding mothers' infant-feeding intentions and behavior: Testing the theory of reasoned action. Journal of Personality and Social Psychology, 44, 657-671.

Maurer, M. \& Simonson, M. (1984). Development of validation of a measure of computer anxiety in M. Simonson (Ed.). Proceedings of Selected Research Paper Presentations. Presented at the annual meeting of the Association for Educational Communications and Technology, Dallas, TX.

Perrin, N. A., \& Rueter, J. G. (1996). Curriculum revision with educational technology: Improving student outcomes in large classrooms. Unpublished manuscript, Portland State University

Reece, M. J., \& Gable, R. K. (1982). The development and validation of a measure of general attitudes toward computers. Education and Psychological Measurement, $\underline{42}, 913-916$

Roth, B., \& Sanders, D. (1996). Instructional technology to enhance teaching New Directions for Higher Education, 94, 21-32.

Smetana, J. B., \& Adler, N. E. (1980). Fishbein's value x expectancy model: An examination of some assumptions. Personality and Social Psychology, 60, 89-96.

Smith, W. J., \& Ely, P. (1994). Campus communications: Electronic solutions for everyday use! Tech Trends, $\underline{39}(2), 32-34$.

Snyder, M., \& Gangestead, S. (1986). On the nature of self-monitoring: Matters of assessment, matters of validity. Journal of Personality and Social Psychology, 51(1), 125-139. 
Spotts, T. H. \& Bowman, M. A. (1995). Faculty use of instructional technologies in higher education. Educational Technology, $\underline{35}, 56-64$.

Stevens, D. J. (1982). Perceptions of computers in education. Association for Education Data Systems Journal, 145(1), 1-15.

Terry, D. J., Gallois, C., \& McCamish, M. (Eds.). (1993). The theory of reasoned action: Its application to AIDS-preventive behaviour. New York: Pergamon Press. 
Educational Technology Page 59

Appendix A

Pre-Course Survey 
Educational Technology Page 60

Fund for the Improvement of Postsecondary Education (FIPSE) Curriculum Revision with Educational Technology:

Improving Student Outcomes in Large Classrooms

\section{Part I}

LAST six digits of your social security number:

$\mathrm{XXX} \cdot-\mathrm{x}^{-}-\ldots$ 


\section{Fund for the Improvement of Postsecondary Education (FIPSE) Curriculum Revision with Educational Technology: Improving Student Outcomes in Large Classes}

\section{CONSENT TO PARTICIPATE}

Thank you for agreeing to paricipate in this study to assess leaming outcomes in the large classroom. You will be asked to provide some general information about yourself, complete two short surveys, one at the beginning of the course, taking about 1015 minutes to complete, and one at the end of the course, laking about 15-20 minutes to complece. At the end of the course you will aiso be asked to complete a course evaluation, taking 5-10 minutes to complete. Some of the items on your final exam will be used to assess ynur learning in this course

We ask you to put the LAST six digits of your social security number on the front of the packit so that we will be ahle match your pre-and post-course scores. Once we have matched chese scores, your identifying aumber will be deleted and all analyses will be done without reference to you or any ocher individual. The information you provide will be kept confidential. Composite information, without refereace to any individuals, will only be shared with your instructor after the final grades are in.

You will not receive any direct benefit from taking part in the study, but the study may belp to increase knowledge that may help ochers in the future. Nancy Perrin (7255058) or John Reuter (725-8342), co-investigators for the study, are available to answer any questions you may have about the study or what you are expected to do.

You do not bave to participate in this study and if you chose nut io do so, It wili avi affect your course grade or relationship with Portland State University.

By completing the surveys and tests you are implying that you have consented to participace in this study.

If you have any concerns or questions about this study, please contact Laurie Skokan at (503) 725-3901. Chair of the Human Subjects Research Committee, or the Office of Grants and Contracts, 105 Neuberger Hall, Porland State University, (503) 725-3417. 


\begin{tabular}{|c|c|c|}
\hline Gender & $-M$ & - \\
\hline Age & years & \\
\hline $\begin{array}{l}\text { What year are you in sctrool? } \\
\text { (Check one) }\end{array}$ & $\begin{array}{l}\text { - Freshman } \\
\text { - Sophmore } \\
\text { - Junior } \\
\text { - Senior } \\
\text { - Post Baccalaureate }\end{array}$ & $\begin{array}{l}\text { - Masters Student } \\
\text { - Doctoral Student } \\
\text { _ Post Graduate } \\
\text { - Not enrolled } \\
\text { _-Other: }\end{array}$ \\
\hline How many cradit hours are you taking this term? & _- indargraduate hours & - graduate hours \\
\hline Do you have significant child or elder care obligations? & -yes _no & _ave workday hrshwk \\
\hline $\begin{array}{l}\text { Are you currenty employed? } \\
\text { If yes, do you use a computer in your work? }\end{array}$ & 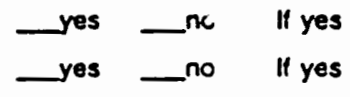 & $\begin{array}{l}\text { —ave hrstwk } \\
\text { — of time }\end{array}$ \\
\hline $\begin{array}{l}\text { Do you own a computer? } \\
\text { If no, do you have have easy access to one? }\end{array}$ & $\begin{aligned} \text { yes } & \text { no } \\
\text { yes } & \text { no }\end{aligned}$ & \\
\hline $\begin{array}{l}\text { What types of operating systems have you morked on? } \\
\text { (Check any that apply) } \\
\text { (Double check the one you use most often) }\end{array}$ & $\begin{array}{l}\text { - Macintosh } \\
\text { - DOS } \\
\text { - Windows }\end{array}$ & $\begin{array}{l}\text { _ Unix } \\
\text { _ vMS } \\
\text { _ Other: }\end{array}$ \\
\hline $\begin{array}{l}\text { How: have une usod a compiter? } \\
\text { (Check any that apply) }\end{array}$ & $\begin{array}{l}\text { _Word prongesing } \\
\text { _Oatabase } \\
\text { _Graphics/Presentation } \\
\text { _Programming } \\
\text { _Statistical packages } \\
\text { _Other: }\end{array}$ & $\begin{array}{l}\text { _Spreadsheot } \\
\text { _o-mall } \\
\text { _Intemennww } \\
\text { _Simulation } \\
\text { _Games }\end{array}$ \\
\hline Do you have an e-mail address? & yes & \\
\hline $\begin{array}{l}\text { Can (could) you access e-mail from home? } \\
\text { Do you have access to Netscape from home? }\end{array}$ & $\begin{array}{r}\text { yes } \\
\text { yes }\end{array}$ & \\
\hline Have you ever been diagnosed with a leaming disability? & yes & \\
\hline Did you complete Frestiman Inquiry or Inquiry Transfer? & _yes & \\
\hline
\end{tabular}


Please Indicate the extent to which you agree or disagree with each of the statements below by marking the number

\begin{tabular}{|c|c|c|c|c|c|c|c|}
\hline & I am sure that I will use a computer in my future occupation. & 1 & 2 & 3 & 4 & 5 & \\
\hline 2 & All college students should have some understanding about computers. & 1 & 2 & 3 & 4 & 5 & 6 \\
\hline 3 & I get a sinking feeling when I think about trying to use a computer. & 1 & 2 & 3 & 4 & 5 & 6 \\
\hline 4 & I like computer problems that I can't understand right away. & 1 & 2 & 3 & 4 & 5 & 6 \\
\hline $\mathbf{s}$ & It is easy for me to understand most technological advances. & 1 & 2 & 3 & 4 & 5 & 6 \\
\hline 6 & I enjoy talking with others about computers. & 1 & 2 & 3 & 4 & 5 & 6 \\
\hline 7 & I sometimes get nervous just thinking about computers & 1 & 2 & 3 & 4 & 5 & 6 \\
\hline 8 & $\begin{array}{l}\text { Having a computer always available to me would improve my } \\
\text { productivity. }\end{array}$ & 1 & 2 & 3 & 4 & 5 & 6 \\
\hline 9 & I have avoided computers because they are unfamiliar to me. & 1 & 2 & 3 & 4 & 5 & 6 \\
\hline 10 & I could get good grades In classes that use computers. & 1 & 21 & 3 & & 5 & 6 \\
\hline 11 & $\begin{array}{l}\text { I hesitate to use a computer for fear of making mistakes I cannot } \\
\text { correct. }\end{array}$ & 1 & 2 & 3 & 4 & 5 & 6 \\
\hline 12 & Computers are valuable educational tools. & 1 & 2 & 3 & 4 & 5 & 6 \\
\hline 13 & $\begin{array}{l}\text { Most things I can handle okay, but I have trouble working with } \\
\text { computers. }\end{array}$ & 1 & 2 & 3 & 4 & 5 & 6 \\
\hline 14 & $\begin{array}{l}\text { If a computer problem was left unsolved after class, I would continue } \\
\text { to work on it. }\end{array}$ & 1 & 2 & 3 & 4 & 5 & 6 \\
\hline 15 & Using a computer is very easy for me. & 1 & 2 & 3 & 4 & 5 & 6 \\
\hline 16 & Once I start working on a computer I find it very hard to stop. & 1 & 2 & 3 & 4 & 5 & 6 \\
\hline 17 & Taking a test on a computer would scare & 1 & 2 & 3 & 4 & 5 & 6 \\
\hline & All college students should understand & 1 & 2 & & & & \\
\hline
\end{tabular}


$1-C$

$\begin{array}{ll}\text { S } & \\ \text { T } & \\ \text { R } & \\ O & \\ \text { N } & \text { S } \\ \text { G } & \text { T } \\ \text { L } & \text { R } \\ \text { Y } & \text { O } \\ & \text { N } \\ \text { D } & \text { G } \\ \text { I } & \text { L } \\ \text { S } & \text { Y } \\ \text { A } & \text { A } \\ \text { G } & \text { G } \\ \text { R } & \text { R } \\ \text { E } & \text { E } \\ \text { E } & \text { G }\end{array}$

Please indicate the extent to which you agree or disagree with each of the statements below by marklng the number that corresponds to your feellngs, oplnion, or experience. I=STRONGLY DISAGREE

2=Moderately Disagree

3-Slightly Disagree

4=Slightly Agree

5= Moderately Agree

G=STRONGLY AGREE

Note: These questions apply to your experiences IN GENERAL

\begin{tabular}{|c|c|c|c|c|c|c|c|}
\hline - & $\begin{array}{l}\text { I prefer classes that challengo me to those in which I can net } 2 \text { a } \\
\text { easy grade. }\end{array}$ & 1 & 2 & 3 & 4 & 5 & 6 \\
\hline 2 & I like leaming about a variety of subjects. & 1 & 2 & 3 & 4 & 5 & 6 \\
\hline 3 & $\begin{array}{l}\text { I often spend time exploring an idea from class that I don'l need } \\
\text { to know for my grade. }\end{array}$ & 1 & 2 & 3 & 4 & 5 & 6 \\
\hline 4 & $\begin{array}{l}\text { I can tell for myself if I learned the subject matter regardless } \\
\text { of the grade I receive. }\end{array}$ & 1 & 2 & 3 & 4 & 5 & 6 \\
\hline \multirow[t]{2}{*}{5} & \multirow{2}{*}{$\begin{array}{l}\text { If I don't understand something in class, I try to figure it out } \\
\text { on my own. }\end{array}$} & 1 & 2 & 3 & 4 & 5 & 6 \\
\hline & & 1 & 2 & 3 & 4 & 5 & 6 \\
\hline 6 & I like classes where I have to work hard to master the material. & 1 & 2 & 3 & 4 & 5 & 6 \\
\hline 7 & I will probably do graduate work after I finish college. & 1 & 2 & 3 & 4 & 5 & 6 \\
\hline
\end{tabular}

Note: These questions should be answered in regard to to THIS CLASS specifically.

\begin{tabular}{|c|c|c|c|c|c|c|c|}
\hline 1 & I feel that I will do well in this class. & 1 & 2 & 3 & 4 & 5 & 6 \\
\hline 2 & Doing weil in this class is important to me. & 1 & 2 & 3 & 4 & 5 & 6 \\
\hline 3 & I think I will enjoy studying for this class. & 1 & 2 & 3 & 4 & 5 & 6 \\
\hline 4 & I plan to work hard at my homework for this class. & 1 & 2 & 3 & 4 & 5 & 6 \\
\hline 5 & I feel confident that I will get a good grade in this class. & 1 & 2 & 3 & 4 & 5 & 6 \\
\hline 6 & I am not very interested in this class. & 1 & 2 & 3 & 4 & 5 & 6 \\
\hline 7 & I have a high standard for my performance in this class. & 1 & 2 & 3 & 4 & 5 & 6 \\
\hline 8 & I think I will enjoy this class. & 1 & 2 & 3 & 4 & 5 & 6 \\
\hline 9 & $\begin{array}{l}\text { I think I will enjoy doing outside readings and projects for } \\
\text { this class. }\end{array}$ & 1 & 2 & 3 & 4 & 5 & 6 \\
\hline 10 & Most of the things I am interested in are not related to this class. & 1 & 2 & 3 & 4 & 5 & 6 \\
\hline 11 & $\begin{array}{l}\text { It will be important to me to really understand the concepts } \\
\text { covered in this class. }\end{array}$ & 1 & 2 & 3 & 4 & 5 & 6 \\
\hline 12 & I plan to keep up with my daily classwork. & 1 & 2 & 3 & 4 & 5 & 6 \\
\hline
\end{tabular}


Please put a check next to the statement that describes your reason for taking this class.

I am taking it as a general requirement for my degree.

It is in my major or minor field of study.

I am tading it as an elective or because of my interest.

It was the only class available in thits time slot. OTHER

Please Indicate which class you would prefer. (Make two check marks)

This class

If you prefer to take THIS CLASS, would you prefer.

This class with technology

a

This class without technology

a

Another class If you prefer to take ANOTHER CLASS, would you prefer:

Another class with technology

ar

Another class without technology 
Educational Technology Page 66

Appendix B

Post-Course Survey 
Fund for the Improvement of Postsecondary Education (FIPSE) Curriculum Revision with Educational Technology: Improving Student Outcomes in Large Classrooms

\author{
Part II
}

LAST six digits of your social security number:

$\mathbf{x} \mathrm{x} \times-\cdots \cdot--$ 


\section{Fund for the Improvement of Postsecondary Education (FIPSE) Curriculum Revision with Educational Technology: Improving Student Outcomes in Large Classes}

\section{CONSENT TO PARTICIPATE}

Thank you for agreeing to participate in this study to assess learning outcomes in the large classroom. You will be asked to provide some general information about yourself, complete two shor surveys, one at the beginning of the course, taking about 1015 minutes to complete, and one at the end of the course, taking about 15-20 minutes to complete. At the end of the course you will also be asked to complete a course evaluation, taking 5-10 minutes to complete. Some of the items on your final exam will be used to aesess your learning in this course.

We ask you to put the LAST six digits of your social security number on the front of the packet so that we will be asle match your pre-and post-course scores. Once we have matched these scores, your identifying number will be deleled and ali aualyses wii bi done without reference to you or any other individual. The information you provide will be kept confidential. Composite information, without reference to any individuals, will only be shared with your instructor after the final grades are in.

$\because \quad$ You will not receive any direct benefit from taking part in the study, but the study may help to increase knowledge that may help others in the future. Nancy Perrin (7255058) or John Reuter (725-8342), co-investigators for the study, are available to answer any questions you may have about the study or what you are expected to do.

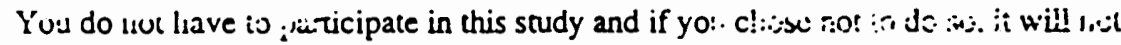
affect your course grade or relationship with Porland State University.

By completing the surveys and tests you are implying that you have consented to paricipate in this study.

If you have any concerns or questions about this study. please contact Laurie Skokan at (503) 725-3901. Chair of the Human Subjects Research Committee, or the Office of Grants and Contracts, 105 Neuberger Hall, Portand State University, (503) 725-3417. 
Please indicate the extent to which you agree or disagree with each of the statements below by marking the number

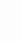

\begin{tabular}{|c|c|c|c|c|c|c|c|}
\hline 1 & I am sure that I will use a computer in my future occupation. & 1 & 2 & 3 & 4 & 5 & 6 \\
\hline 2 & All college students should have soine understariding abnut computers & 1 & 2 & 3 & 4 & 5 & 6 \\
\hline 3 & I get a sinking feeling when I think about trying to use a computer. & 1 & 2 & 3 & 4 & 5 & 6 \\
\hline 4 & I like computer problems that I can't understand right away. & 1 & 2 & 3 & 4 & 5 & 6 \\
\hline 5 & It is easy for me to understand most technological advances. & 1 & 2 & 3 & 4 & 5 & 6 \\
\hline 6 & I enjoy talking with others about computers. & 1 & 2 & 3 & 4 & 5 & 6 \\
\hline 7 & 1 sometimes get nervous just thinking about computers & 1 & 2 & 3 & 4 & 5 & 6 \\
\hline 8 & $\begin{array}{l}\text { Having a computer always available to me would improve my } \\
\text { productivity. }\end{array}$ & 1 & 2 & 3 & 4 & 5 & 6 \\
\hline 3 & : have s:oided computers because thry ars unfamiliar to me & 1 & 2 & 3 & $\therefore$ & 5 & 6 \\
\hline 10 & I could get good grades in classes that use computers. & 1 & 2 & 3 & 4 & 5 & 6 \\
\hline 11 & $\begin{array}{l}\text { I hesitate to use a computer for fear of making mistakes I cannot } \\
\text { correct. }\end{array}$ & 1 & 2 & 3 & 4 & 5 & 6 \\
\hline 12 & Computers are valuable educational tools. & 1 & 2 & 3 & 4 & 5 & 6 \\
\hline 13 & $\begin{array}{l}\text { Most things I can handle okay, but I have trouble working with } \\
\text { computers. }\end{array}$ & 1 & 2 & 3 & 4 & 5 & 6 \\
\hline 14 & $\begin{array}{l}\text { If a computer problem was left unsolved after class, I would continue } \\
\text { to work on it. }\end{array}$ & 1 & 2 & 3 & 4 & 5 & 6 \\
\hline 15 & Using a computer is very easy for me. & 1 & 2 & 3 & 4 & 5 & 6 \\
\hline 16 & Once I start working on a computer I find it very hard to stop. & 1 & 2 & 3 & 4 & 5 & 6 \\
\hline 17 & Taking a test on a computer would scare me. & 1 & 2 & 3 & 4 & 5 & 6 \\
\hline 18 & All college students should understand the role computers play in society. & 1 & 2 & 3 & 4 & 5 & 6 \\
\hline
\end{tabular}


Please Indicate the extent to which you agree or disagree with es:il oi the stat.sments jeiow by inaiking the number that corresponds to your feelings, opinion, or experience. $1=$ STRONGLY DISAGREE 2=Moderately Disagis: $3=$ Slightly Disagree $4=$ Slightly Agree $5=$ Moderately Agree $6-S T R O N G L Y$ AGREE

:

Note that these questions should be answered in regard to THIS CLASS specifically.

\begin{tabular}{|c|c|c|c|c|c|}
\hline \multicolumn{6}{|c|}{$\mathbf{S}$} \\
\hline \multicolumn{6}{|c|}{$T$} \\
\hline \multicolumn{6}{|c|}{$R$} \\
\hline 0 & & & & & $\mathbf{S}$ \\
\hline$N$ & & & & & $\mathbf{T}$ \\
\hline $\mathbf{G}$ & & & & & $\pi_{i}$ \\
\hline$L$ & & & & & 0 \\
\hline$Y$ & & & & & $\mathbf{N}$ \\
\hline & & & & & $c$ \\
\hline D & & & & & $\mathbf{L}$ \\
\hline I & & & & & $\mathbf{Y}$ \\
\hline $\mathbf{S}$ & & & & & \\
\hline A & & & & & $A$ \\
\hline $\mathbf{G}$ & & & & & $\mathbf{G}$ \\
\hline$R$ & & & & & R \\
\hline $\boldsymbol{E}$ & & & & & $\mathbf{E}$ \\
\hline$E$ & & & & & $\mathbf{E}$ \\
\hline 1 & 2 & 3 & 4 & 5 & 6 \\
\hline 1 & 2 & 3 & 4 & 5 & 6 \\
\hline 1 & 2 & 3 & 4 & 5 & 6 \\
\hline 1 & 2 & 3 & 4 & 5 & 6 \\
\hline 1 & 2 & 3 & 4 & 5 & 6 \\
\hline 1 & 2 & 3 & 4 & 5 & 6 \\
\hline 1 & 2 & 3 & 4 & 5 & 6 \\
\hline 1 & 2 & 3 & 4 & 5 & 6 \\
\hline 1 & 2 & 3 & 4 & 5 & 6 \\
\hline 1 & 2 & 3 & 4 & 5 & 6 \\
\hline 1 & 2 & 3 & 4 & 5 & 6 \\
\hline 1 & 2 & 3 & 4 & 5 & 6 \\
\hline
\end{tabular}

\begin{tabular}{|c|c|c|c|c|c|c|c|}
\hline 1 & I feel that I did well in this class. & 1 & 2 & 3 & 4 & 5 & 6 \\
\hline 2 & 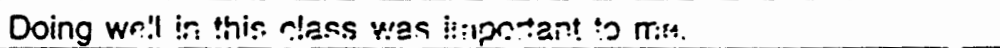 & 1 & 2 & 3 & 4 & 5 & 6 \\
\hline 3 & I enjoyed studying for this class. & 1 & 2 & 3 & 4 & 5 & 6 \\
\hline 4 & I worked hard at my homework for this class. & 1 & 2 & 3 & 4 & 5 & 6 \\
\hline 5 & I feel confident that I got a good grade in this class. & 1 & 2 & 3 & 4 & 5 & 6 \\
\hline 6 & I was not very interested in this class. & 1 & 2 & 3 & 4 & 5 & 6 \\
\hline 7 & I had a high standard for my performance in this class. & 1 & 2 & 3 & 4 & 5 & 6 \\
\hline 8 & I enjoyed this class. & 1 & 2 & 3 & 4 & 5 & 6 \\
\hline 9 & I enjoyed doing outside readings for this class. & 1 & 2 & 3 & 4 & 5 & 6 \\
\hline 10 & Most of the things 1 am interested in are not related to this class & 1 & 2 & 3 & 4 & 5 & 6 \\
\hline 11 & $\begin{array}{l}\text { It was important to me to really understand the concepts } \\
\text { covered in this class. }\end{array}$ & 1 & 2 & 3 & 4 & 5 & 6 \\
\hline 12 & I kept up with my daily classwork. & 1 & 2 & 3 & 4 & 5 & 6 \\
\hline
\end{tabular}


II-C

Please compare both statements before marking your answer

$i=1$ agree with the statement on the LEFT.

$2=1$ agree (with reservations) with the statement on the left $3=1$ have no preference for either statement

$4=1$ agree (with reservations) with the statement on the right $5=1$ agree with the statement on the RIGHT

1. When reading for this course

$\begin{array}{llll}1 & 2 & 3 & 4\end{array}$

When reading for this course

I tended to concentrate on

I tended to follow the author's certain parts and skip over presentation reasonably others, going back later if necessary to fill in any closely, rather than skipping . around a lot.

gaps or missing links.

2 Generally I preferred to $\begin{array}{llllll}1 & 2 & 3 & 4 & 5 & \text { Generally I preferred to be }\end{array}$ concentrate on one (or learnir:s about a very few) aspect(s) number of different of this subject at a time aspects of this subject when I was learning about it. at the same time.

3 I like to approach a new $\begin{array}{llllll}1 & 2 & 3 & 4 & 5 & \text { I like the logical links between }\end{array}$ subject in a broad way, often looking at widely spaced aspects of the subiect and seeing how they fit together before going back to fill in any steps I may have missed. different aspects of a new subject to be very close so that when I am learning about a second aspect I can see clearly how it relates to the first aspect.

4 I like to deal thoroughly $\begin{array}{llllll}1 & 2 & 3 & 4 & 5 & 1 \text { find it too restrictive to }\end{array}$ with the particular aspect wait until I have thoroughly I am working on before mastered one aspect of a going on to others. new subject before going on to study other aspects. 
Please indicate which class you would have preferred. (Make 2 check marks)

This class If you preferred to take THIS CLASS, would you have preferred:

This class with technology
CR
This class without technology

QR Another class

If you preferred to take ANOTHER CLASS, would you have preferred

_ Anvither c!ass with teshnviagy

QR

Another class without technology 


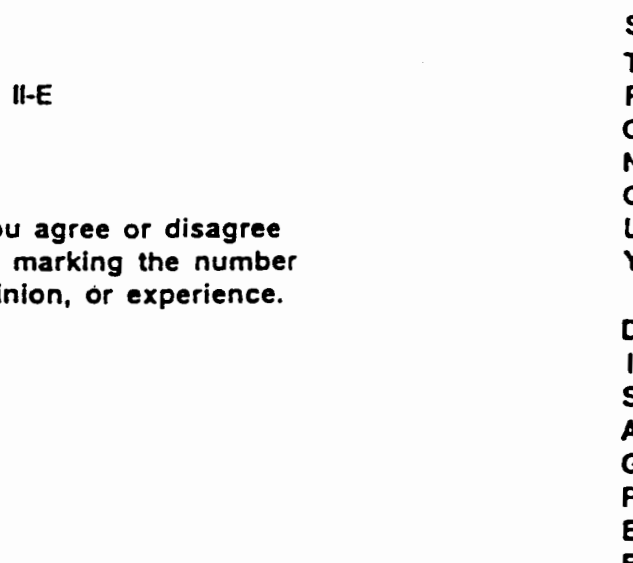

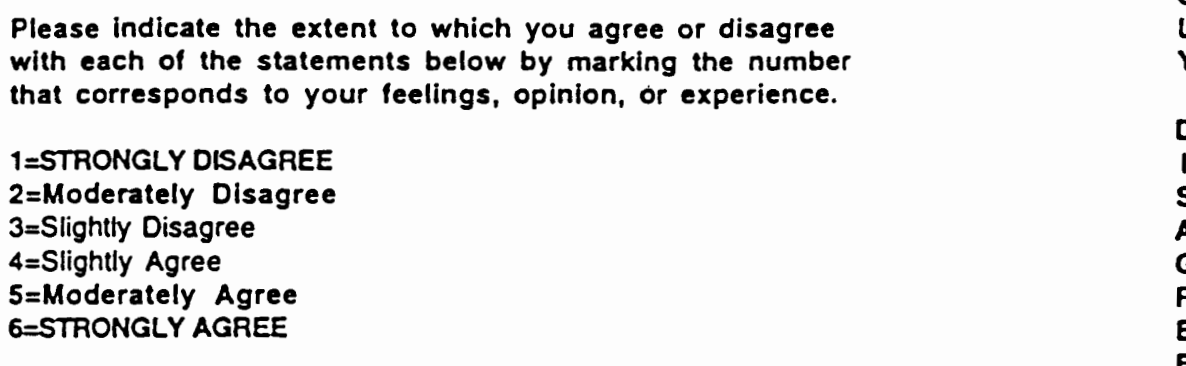

s

$\mathbf{T}$

R

O S

$N \quad T$

G $R$

$\gamma \quad O$

N

L

$Y$

$A$

$G$

R

\begin{tabular}{|c|c|c|c|c|c|c|c|}
\hline 1 & The instructor communicated interesventhusiasm about the subject. & 1 & 2 & 3 & 4 & 5 & 6 \\
\hline 2 & The instructor's presentations were clear and understandable. & 1 & 2 & 3 & 4 & 5 & 6 \\
\hline د) & The instructor encuuidged discussion ind questioris. & 1 & 2 & 3 & 4 & 5 & 6 \\
\hline 4 & $\begin{array}{l}\text { The various aspects of the course (lectures, readings, etc.) were } \\
\text { well integratec. }\end{array}$ & 1. & 2 & 3 & 4 & 5 & 6 \\
\hline s) & $\begin{array}{l}\text { Appropriate attention was devoted to differing opinions and } \\
\text { approaches to the subject matter. }\end{array}$ & 1 & 2 & 3 & 4 & 5 & 6 \\
\hline 6 & The instructor's reponses to student's questions were clear. & 1 & 2 & 3 & 4 & 5 & 6 \\
\hline 7 & The instructor challenged/encouraged my thinking. & 1 & 2 & 3 & 4 & 5 & 6 \\
\hline 8 & The instructor was fully prepared when presenting material. & 1 & 2 & 3 & 4 & 5 & 6 \\
\hline. & The instructor was knowledgeable and confident about the subject. & 1 & 2 & 3 & 4 & 5 & 6 \\
\hline 10 & Course objectives and expectations were made clear. & 1 & 2 & 3 & 4 & 5 & 6 \\
\hline 11 & The instructor was fair in grading. & 1 & 2 & 3 & 4 & 5 & 6 \\
\hline 12 & The exams covered material emphasized in class. & 1 & 2 & 3 & 4 & 5 & 6 \\
\hline is] & I received useful feedback about my performance. & 1 & 2 & 3 & 4 & 5 & 6 \\
\hline 14 & The instructor was genuinely interested in having students learn. & 1 & 2 & 3 & 4 & 5 & 6 \\
\hline 15 & The instructor was available to spend extra time with students. & 1 & 2 & 3 & 4 & 5 & 6 \\
\hline 16 & I increased my understanding of the subject. & 1 & 2 & 3 & 4 & 5 & 6 \\
\hline 17 & The class was a worthwhile learning experience. & 1 & 2 & 3 & 4 & 5 & 6 \\
\hline 18 & $\begin{array}{l}\text { Feedback from the classroom assessment exercises was valuable } \\
\text { to my learning. }\end{array}$ & 1 & 2 & 3 & 4 & 5 & 6 \\
\hline & $\begin{array}{l}\text { Because of this class I am more confident that I can reach my } \\
\text { academic goals. }\end{array}$ & 1 & 2 & 3 & 4 & 5 & 6 \\
\hline & The classroom assessment & & & & & & \\
\hline
\end{tabular}


Please indicate the extent to which you agree or disagree with each of the statements below by marking the number that corresponds to your feelings, opinion, or experience.

N

21 Technology enhanced my ability to leam the material.

.22 found the use of multiple multi-media images to be overwhelming.

23 The use of e mail was valuable to my learning in this course.

24 I spent too much time trying to leam to use the technology.

2s I useo technology tha! I leamed in class outside the context of this class.

26 I was at a disadvantage in this class because I do not possess

adequate computer skills.

27 Because of technology I was better able to visualize the ideas and concepts that were taught in the course.

20 The use of Intemet was valuable to my leaming in this class.

29 Technology created a barrier between the professor and the students.

so E-mail made it easier for me to ask questions and receive responses

from tha professor.

31 E-mail helped me communicate with other students in the class about course material.

32 Because of the technology I spent more time studying for this course than I would have otherwise.

J The aspect that I found most beneficial about the use of technology was:

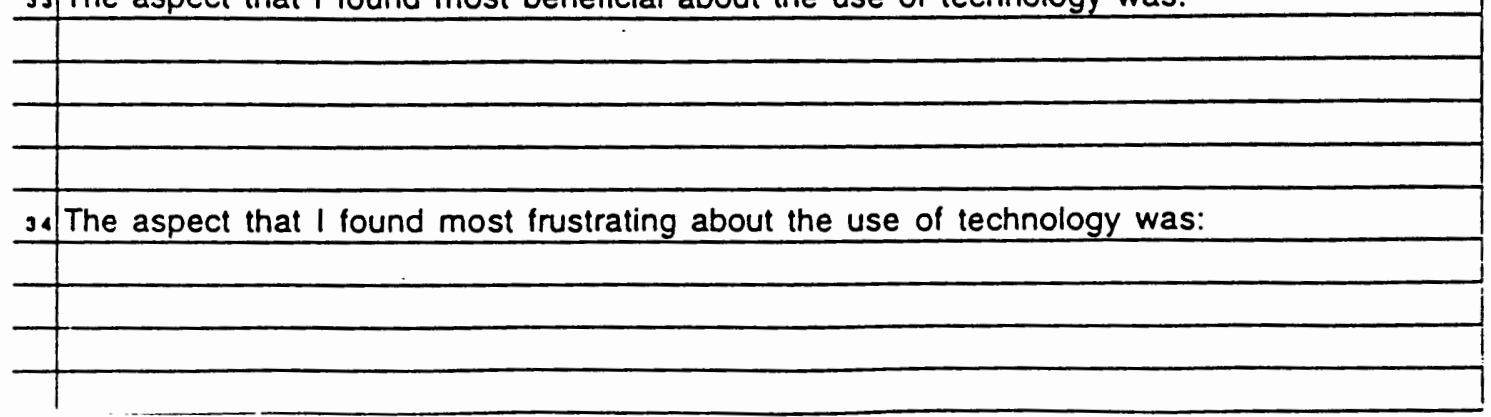

